\title{
Game Models on Optimal Strategies in a Tourism Dual-Channel Supply Chain
}

\author{
Lei Yang, ${ }^{1}$ Jingna Ji, ${ }^{1}$ and Kebing Chen ${ }^{2}$ \\ ${ }^{1}$ School of Economics and Commerce, South China University of Technology, Guangzhou, Guangdong 510006, China \\ ${ }^{2}$ Department of Mathematics, Nanjing University of Aeronautics and Astronautics, Nanjing, Jiangsu 210016, China \\ Correspondence should be addressed to Lei Yang; yang@scut.edu.cn
}

Received 1 March 2016; Accepted 21 April 2016

Academic Editor: Luca Guerrini

Copyright (c) 2016 Lei Yang et al. This is an open access article distributed under the Creative Commons Attribution License, which permits unrestricted use, distribution, and reproduction in any medium, provided the original work is properly cited.

\begin{abstract}
This paper explores a two-echelon tourism supply chain consisting of a hotel and an online travel agency. The upside hotel rooms can be sold through the downside hotel alliance and online travel agency. The hotel alliance, selling rooms at a lower price, is a direct sale platform with a negligible entry fee. Notwithstanding, the online travel agency sells the room at a higher price with related personalized service. Customers will be refunded partially in case of their cancellation or no-show. An integrated model and two decentralized models based on Bertrand and Stackelberg games are developed, respectively. The results show that when the wholesale price is lower than a certain value, both the hotel and the online travel agency can gain more profit from the Stackelberg game than that from the Bertrand game. In the case that the hotel allows overbooking, the optimal overbooking quantity is obtained. If the overbooking proportion is too high, overbooking is profitable for the hotel only when the overbooking cost is lower than a certain value. At the end of the study, some experiments are conducted to analyze the sensitivity of the optimal prices and profits in the light of certain parameters.
\end{abstract}

\section{Introduction}

The improvement of transport infrastructure has significantly reduced the trip cost and promoted the development of tourism [1]. In recent years, the tourism industry has evolved considerably and plays an essential role in local economic development. In the supply chain management, specifically, tourism has never been so much concerned by academic researchers and industry practitioners since it provides a new perspective for the tourism firms to improve their competitiveness. As we all know, supply chain management is a kind of process to increase the efficiency of a supply chain network via conducting and integrating fund, information, and goods flows from suppliers to end customers [2]. The tourism supply chain is defined as a network of tourism organizations engaged in different activities ranging from the supply of tourism products or services such as flights and accommodation to the distribution and marketing of the final tourism product at a specific tourism destination [3]. In China, for example, the hotel industry is one of the fastest growing worldwide, with revenue increasing 1.8 times during the period from 2000 to 2009 [4]. Therefore, we study the tourism supply chain involving hotels.

The development of Internet has provided a strong incentive for manufacturers to engage in direct sales. The providers of tourism products are also inclined to build dualchannels. By the end of December 2015, China has had 688 million Internet users, among which there are 260 million online travel product users (http://cnnic.cn/gywm/xwzx/ rdxw/2015/201601/W020160122639198410766.pdf). On the other hand, in 2014, the online tourism market transactions totaled 307.79 billion yuan, which increases by $38.9 \%$ comparing with the same period in 2013 (http://report .iresearch.cn/report/201504/2341.shtml). The Internet has been widely used by travelers as a crucial channel for booking hotel rooms [5]. Hotels, therefore, usually provide two booking channels, the online travel agency (OTA) and the hotel alliance (HA).

OTA, as an intermediary between hotels and customers, plays an essential role in the tourism supply chain, such as 
Ctrip.com, eLong.com, and Mangocity.com. However, a common phenomenon is that hotels must pay high commission for each sold room [6, 7]. In order to reduce commission fees and sell rooms to customers directly, hotels join a HA, where the HA can be regarded as a direct sales platform. For instance, WeChat public platform and alitrip.com offer the direct selling platforms for hotels. Compared with developing official websites, joining $\mathrm{HA}$ can help the hotels reduce cost. Hotels have not been benefited much from website development investment [8]. Take, for example, Four Seasons hotel; it has invested 18 million for its new website while online revenue only increases by $2 \%$ in five years [9]. On the contrary, hotels can pay 0 to 15000 yuan per year to join the alitrip.com, so as to deal with orders through this website directly. Generally speaking, the reservation price through the alliance is up to $20 \%$ to $70 \%$ of the rack rate. In the light of the uncertain factors such as time, city, room type, and room quantity, the discount is not fixed. In most cases, the price of $\mathrm{HA}$ is $10 \%$ to $30 \%$ lower than OTA, except for a plan of promotion, with the extent to which the price will be equal to that of OTA. Pricing competition exists between the two channels. Therefore, how to determine the pricing decisions has much practical significance for hotels.

Customer cancellations and no-show occur frequently in the yield management of hotel reservations [10]. Once customers cancel the reservation or fail to show up, the hotel will suffer loss for the rooms. That is because rooms are perishable products. In order to deal with this case, the hotel usually permits overbooking. However, overbooking will bring a risk that the actual booking quantity is greater than the number of hotel rooms. As a result, the overbooking costs must be paid. A question therefore arises as to how a hotel determines the overbooking quantity so as to keep a balance between the vacancy lost and the overbooking costs.

Since more and more hotels employ dual-channel structure, we develop a two-echelon tourism supply chain model involving one hotel and one OTA to study hotel room pricing strategies, with which OTA provides related service. Bertrand and Stackelberg game models are both analyzed. Furthermore, this paper considers customers' no-show phenomenon in a dual-channel setting under tourism supply chain. The results of the study will assist hotels to manage and optimize their pricing decisions.

The remainder of this paper is organized as follows: Section 2 provides a literature review and Section 3 presents notations. Section 4 analyzes the integrated tourism supply chain. Section 5 shows the Bertrand and Stackelberg game models, respectively. The overbooking situation is illustrated in Section 6. Section 7 conducts numerical experiments to provide more insights. Conclusions and outlooks are finally presented in Section 8. To make the paper more readable, all proofs are presented in Appendix.

\section{Literature Review}

This research is closely related to tourism supply chain, pricing strategies in dual-channel supply chain, and revenue management. To highlight our contributions, we review only the literature that is representative and particularly relevant to our study.

2.1. Tourism Supply Chain Management. Tourism supply chain management has been studied since the 1990s. For example, Yang et al. [11] utilized game theory to investigate the cooperation and competition between two tourism supply chains, which consist of service providers, a theme park operator, and accommodation providers. They concluded that, in order to optimize performance, the decision makers of the two tourism supply chains are expected to adopt appropriate product differentiation strategies. Differently, we highlight the comparison between the Bertrand and Stackelberg game in a two-echelon tourism supply chain. Huang et al. [12] did research on competition strategies in a tourism supply chain network consisting of theme parks, accommodation providers, and tour operators, which are involved in producing and providing package holidays. They analyzed the differences between the impacts of quantity and price competitions. Huang et al. [13] studied the impact of the involvement of tour operators in a tourism supply chain with multiple hotels and travel agencies and showed that when the market size of travel agencies is lower than a certain level, both travel agencies and the hotel can benefit more from the presence of a tour operator in a tourism supply chain. Similarly, we focus on the supply chain involving hotels and tour operators. However, our contributions are directed to formulating a dual-channel environment by considering the no-show phenomenon. Furthermore, Lee and Fernando [14] developed a model for the medical tourism supply chain and showed that supply chain coordination and information sharing have a direct effect on organizational performance. We aim to contribute to this stream of literature by considering hotels' pricing decisions under dual-channel structure.

2.2. Pricing Strategies in Dual-Channel Supply Chain. The research on dual-channel supply chain management has gained much attention among the marketing and supply chain management. In particular, the studies focusing on pricing strategies are closely related to our study. In this aspect, Chiang et al. [15] make a great contribution. They constructed a price-setting game between a manufacturer and its independent retailer. They pointed out that the direct sales channel can help the manufacturer improve overall profitability by reducing the degree of inefficient price double marginalization. Tsay and Agrawal [16] found that the manufacturer can coordinate the supply chain and achieve a win-win situation through adjusting the direct price. Q.-H. Li and B. Li [17] studied a dual-channel supply chain in which the retailer provides value-added services to products. Their results indicate that the entire supply chain cannot be coordinated with a constant wholesale price when the retailer provides value-added services and has fairness concerns. Similarly, we also assume that the OTA adds additional value to the tourism product. Panda et al. [18] explored pricing and replenishment policies for a hightech product in a dual-channel supply chain that consists of a brick-and-mortar channel and an internet channel. 
Liu et al. [19] investigated the pricing decisions under dualchannel structure. In their model, fairness and free-riding behavior are considered. They detected that manufacturer's equilibrium price based on channel fairness is below its equilibrium price ignoring fairness. More related articles on this issue have been presented by Chen et al. [20], Ding et al. [21], and Rodriguez and Aydin [22].

2.3. Revenue Management. Revenue management, which was originated in the airline industry, is also widely used in the hotel industry. That is because airline and hotel have similar characteristics (e.g., perishable service or product, fixed capacity, distinct customer segmentation, and price differentiation). In this aspect, the room pricing decision has been studied extensively since price has an important influence on customer's accommodation selection decisions [23]. It is also relevant to our study.

Chen et al. [24] examined the impact of hotel pricing on guest satisfaction. Their results imply that, at the low price level, room price and food and beverage price lead to an increase in guest satisfaction, whereas the high price level could have just the opposite effect. Ling et al. [6] considered the case that customers can make reservations directly through the distribution channel of the hotel or indirectly through the OTA. Although the background of the study is similar to that in our model, they aim to find a method for hotels to manage their room availability for cooperative OTAs. Espinet et al. [25] analyzed how hotel characteristics affect seasonality in prices and find that more hotel services and higher star ratings are associated with fewer seasonal variations in hotel prices. Juaneda et al. [26] investigated the price component of physical characteristics and the location of apartments and hotels and compare their effect on the final price of both types of accommodation. Abrate et al. [27] collected data from almost 1000 hotels in Europe to analyze the dynamic pricing strategies of hotels; they showed that the intertemporal pricing structure primarily depends on the type of customer, the star rating, and the number of suppliers with available rooms.

The extant literature about revenue management is mostly from the perspective of the hotel itself. However, nowadays, the competition among tourism enterprises turns to be gradually and distinctly embodied in the competition among their tourism supply chains. In contrast to the above papers, our model is more practical by considering pricing strategies from the perspective of tourism dual-channel supply chain.

This paper makes the following contributions. Firstly, this paper introduces the tourism products into the dual-channel supply chain framework while the aforementioned literature ignores this point. Secondly, the rooms in our research are classified into economic and luxury type, which can be better to reflect the reality. Thirdly, this paper aims to illustrate the pricing decisions under several common cases, which can provide a valuable reference for hotels and OTAs.

\section{Model Setup and Notations}

We consider a tourism supply chain model involving one hotel and one OTA (Figure 1). The hotel and OTA are both

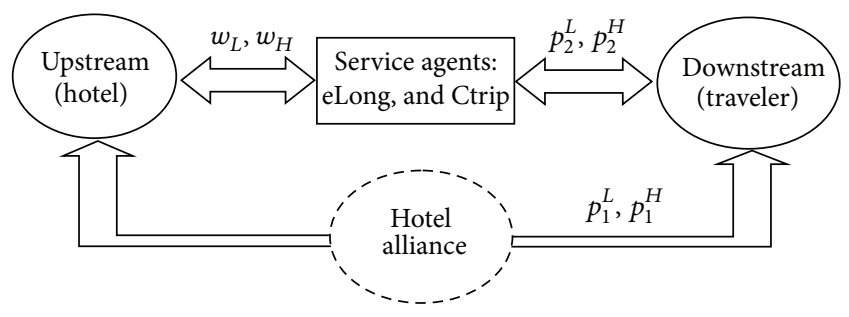

FIgURE 1: Tourism dual-channel supply chain model diagram.

risk neutral and completely rational. The hotel is required to sign a cooperation agreement to join a HA. However, HA charges the hotel trivial commissions. Thus, HA can be treated as a hotel's direct sales platform and HA's price is decided by the hotel directly. Therefore, it is negligible to consider the contractual relationship between the hotel and HA.

For the hotel, customers are usually divided into two types: business travelers and leisure travelers. Leisure travelers are more sensitive to room price than business ones so that they often make a reservation before a long time. Accordingly, hotels prefer to sell luxury rooms to business travelers. Correspondingly, the hotel rooms are usually classified according to different customers' need, such as luxury rooms, economy rooms, standard rooms, and business rooms. Through setting different rates for different rooms, hotels are able to sell different types of rooms to specific target customers. Based on the above background, in our model, the hotel rooms are classified into economic and luxury type. In this paper, hotel sells room means that hotel sells the right for guest to use the room; that is, the hotel rents the room to guest for a period of time. The hotel sells the economy (luxury) rooms with the price of $p_{1}^{L}\left(p_{1}^{H}\right)$ to the customer directly, and it sells rooms to OTA with the wholesale prices of $w_{L}\left(w_{H}\right)$, respectively. Providing combination of products and additional services, OTA sells rooms to customers with the prices of $p_{2}^{L}$ and $p_{2}^{H}$.

According to international practice, in order to reduce the phenomenon of no-show, customers must provide hotel reservation deposit with credit card or prepay the fee when they make reservation. If customers cancel the booking or choose no-show, the hotel can deduct all or part of the room charge. Take, for example, Ctrip.com; the orders can be divided into two types: orders that cannot be cancelled and time-limited orders. When customers choose the orders that cannot be cancelled, they cannot cancel the order after they conform the booking; if not, the reservation deposit or prepaid fee will not be returned. This kind of situation usually occurs when guest room resources are intense. The timelimited order means that customers can cancel the order for free before the deadline (usually 1 to 3 days before check-in). If customers cancel the booking after the deadline or choose noshow, Ctrip.com will charge the customers for the first day's room fee as a punishment. This also means that when the customer reserves a room for more than one day, he will receive partial refund. Such methods are also adopted by Booking.com and eLong.com. Based on reality, we assume that customers must provide full guarantee with credit card when they make reservation, but if the customers cancel 
the booking or choose no-show finally, the hotel would only return certain expense rate of $\alpha(0 \leq \alpha \leq 1)$. If a customer is booking through OTA, then OTA would return to the customer with the proportion of the retail prices. At the same time, the hotel would return to OTA with the proportion of the wholesale prices. We assume that the proportion that hotel returns to the customer, the proportion that hotel returns to OTA, and the proportion that OTA returns to the customer are the same.

We list the following notations, where $i(i=L, H)$ in subscripts or superscripts are for economic (low price) and luxury (high price) rooms, respectively.

Q: the total number of rooms provided for renting to guests.

$Q_{i}$ : the total number of economic/luxury rooms.

$D_{1}^{i}$ : the reservation amount of economic/luxury room booking through HA.

$D_{2}^{i}$ : the reservation amount of economic/luxury room booking through OTA.

$a_{i}$ : the market base demand of economic/luxury room.

$a$ : the total market base demand of rooms $\left(a=a_{L}+\right.$ $\left.a_{H}\right)$.

$s$ : the market share of HA in the tourism dual-channel supply chain.

$p_{1}^{i}$ : HA's price of economic/luxury rooms, that is, the direct selling prices.

$p_{2}^{i}$ : OTA's price of economic/luxury rooms, that is, the retail prices.

$w_{i}$ : the wholesale price of economic/luxury rooms.

$b_{i}$ : the price sensitivity coefficient of $i$ price rooms $\left(b_{L}>b_{H}\right)$.

$\theta$ : the diffusion intensity, which describes the shift between two channels with regard to the price and value.

$\lambda$ : the proportion of customer cancellations and noshow.

$\alpha$ : the return expense proportion of customer cancellations and no-show $(0 \leq \alpha \leq 1)$.

$\beta$ : the services elasticity of demand.

$v$ : the value added by OTA's services.

$\eta$ : the coefficient of service cost.

$c(v)$ : the function of service cost, $c(v)=\eta v^{2} / 2$.

$\pi_{1}$ : the profit of the hotel.

$\pi_{2}$ : the profit of the OTA.

In the model, we do not consider the marginal sales cost of the hotel since it is very low. In reality, OTA will firstly introduce to customers the hotels' facilities and quota and afterwards confirm the booking and finally book rooms from the hotel for customers. Therefore, the rooms sold by HA and
OTA are homogeneous. In addition to providing hotel reservations, OTA also provides other related services as well, such as offering plane ticket booking, holiday booking, and travel information. OTA aims to provide a full range of travel program for travelers. In order to provide such services, OTA needs to pay for additional operating costs. The customers who want to get more tourist information and services will prefer to reserve rooms through OTA. By contrast, HA only provides hotel room information for customers. For instance, customers cannot book the suitable hotel and air ticket at the same time through the HA platform. Consequently, in order to distinguish the influence of different information services to customer's channel choice, we suppose that OTA provides additional service and the value added from the services is $v$. Further, the cost for providing service is $c(v)=\eta v^{2} / 2$, where the parameter $\eta$ measures the cost effectiveness of the service. Such cost function is commonly adopted in previous literature and can well describe the relationship between additional services and cost $[28,29]$. When OTA does not provide the service, the cost should be zero.

According to the process of demand function in Tsay and Agrawal [30] and Choi [31], the demands of economic/luxury rooms through each channel are expressed as follows:

$$
\begin{aligned}
& D_{1}^{i}=\left(s a_{i}-b_{i} p_{1}^{i}\right)+\theta\left(p_{2}^{i}-v-p_{1}^{i}\right) \\
& D_{2}^{i}=\left[(1-s) a_{i}-b_{i} p_{2}^{i}\right]+\beta v+\theta\left(p_{1}^{i}+v-p_{2}^{i}\right) .
\end{aligned}
$$

Such linear demand functions are used because they can achieve approximate and satisfactory fit to certain types of demand, and they are tractable and widely used in marketing and supply chain management literature [32]. In our model, the parameter $b$ represents the price sensitivity coefficient. It describes the marginal channel demand per respective channel price. The own price elasticity is normally negative [33]. And the parameter $\beta$ measures the marginal demand of OTA per service value added. In addition, the parameter $\theta$ is understood as the diffusion intensity (cross-price sensitivity) and describes the shift between two channels with regard to the price and the value. Such modeling method can guarantee that the self-price sensitivity, in absolute value, is stronger than the cross-price sensitivity, which is proved by Hanssens et al. [34] and used by Yao and Liu [28], Choi [31], and Kurata et al. [35].

Now consider the situation without overbooking; that is, $D_{1}^{L}+D_{2}^{L} \leq Q_{L}$ and $D_{1}^{H}+D_{2}^{H} \leq Q_{H}$. Thus, the reservation amount can be regarded as the final demand.

The total profit for the hotel, OTA, and the whole supply chain can be expressed as follows:

$$
\begin{aligned}
\pi_{1}= & (1-\lambda \alpha)\left(p_{1}^{L} D_{1}^{L}+p_{1}^{H} D_{1}^{H}+w_{L} D_{2}^{L}+w_{H} D_{2}^{H}\right), \\
\pi_{2}= & {\left[(1-\lambda \alpha)\left(p_{2}^{L}-w_{L}\right)-c(v)\right] D_{2}^{L} } \\
& +\left[(1-\lambda \alpha)\left(p_{2}^{H}-w_{H}\right)-c(v)\right] D_{2}^{H}, \\
\pi= & \pi_{1}+\pi_{2} .
\end{aligned}
$$




\section{Integrated System}

As a benchmark, we first consider an integrated system where the common goal of supply chain upstream and downstream members is to maximize the overall profit of the supply chain. This is an ideal model that the members in the supply chain operate as an entirety. In such an integrated model of tourism supply chain, the hotel and OTA cooperate to determine the pricing strategies.

Proposition 1. In the integrated system, the optimal pricing decisions of HA and OTA are as follows:

$$
\begin{aligned}
p_{1}^{i *}= & \frac{a_{i}\left(b_{i} s+\theta\right)+\theta v\left(\beta-b_{i}\right)}{2\left(b_{i}\right)^{2}+4 b_{i} \theta}, \\
p_{2}^{i *}= & \frac{\left(b_{i}+\theta-b_{i} s\right) a_{i}+b_{i} \beta v+\theta v\left(\beta+b_{i}\right)}{2\left(b_{i}\right)^{2}+4 b_{i} \theta} \\
& +\frac{c(v)}{2(1-\lambda \alpha)},
\end{aligned}
$$

$$
i=L, H \text {. }
$$

From Proposition 1, the optimal prices shown above can explain that in the integrated system the optimal prices of HA will not be affected by the proportion of customer cancellations and no-show $(\lambda)$ or the return expense proportion $(\alpha)$. On the other hand, with the increase of $\lambda$ or $\alpha$, the optimal prices for OTA will increase. This is reasonable because when OTA faces unstable demand or it should return more to customers' cancellation or no-show, it would like to increase the price to guarantee its profit.

Corollary 2. $p_{2}^{L *}$ and $p_{2}^{H *}$ are increasing in $v$. Moreover,

(1) if $\beta>b_{L}>b_{H}$, then $\partial p_{1}^{L *} / \partial v>0, \partial p_{1}^{H *} / \partial v>0$,

(2) if $b_{L}>\beta>b_{H}$, then $\partial p_{1}^{L *} / \partial v<0, \partial p_{1}^{H *} / \partial v>0$,

(3) if $b_{L}>b_{H}>\beta$, then $\partial p_{1}^{L *} / \partial v<0, \partial p_{1}^{H *} / \partial v<0$.

From Corollary 2, we can know that when OTA offers more services, OTA's optimal price will be increased accordingly. It is reasonable that if $v$ increases, the cost of OTA will also definitely increase. So there is always a positive correlation between OTA's optimal prices and the added value.

If $\beta>b_{L}>b_{H}$, the market of economy rooms and that of luxury rooms are both service-oriented rather than price-oriented. The implication is that the effective service will increase the optimal price of HA. When OTA offers more effective service, its price will increase. But some customers want to enjoy the additional services, so they are willing to make a booking through OTA despite spending more money. Therefore, the demand in OTA will increase while the demand in HA will decrease.

If $b_{L}>\beta>b_{H}$, the market of economy rooms is serviceoriented, while the market of luxury rooms is price-oriented. The HA's optimal price of economy rooms will decrease with respect to $v$. Conversely, the HA's optimal price of luxury rooms will increase with respect to $v$. For examples, the change of price has a great impact on leisure travelers' decisions, but for business travelers, the price is not the most concern. If the price of OTA increases, OTA's demand of economy rooms will significantly reduce and the HA's demand will increase, thus the HA's optimal price will decline. On the other hand, for luxury rooms, if OTA provides more effective service, the customer would be willing to pay higher prices for value-added service. This will bring the increase in OTA's demand and the reduction of HA's demand, thus the optimal price of HA will increase.

If $b_{L}>b_{H}>\beta$, the market of economy rooms and that of luxury rooms are both price-oriented than service-oriented. The HA's optimal price of both economy rooms and luxury rooms will decrease with the increase of $v$. When the market is price-oriented, the promotion of price in OTA will lead to a reduction in OTA's demand. Thereby, the demand in HA will increase and optimal price in HA will decline.

\section{Two Game Models}

In the tourism dual-channel supply chain, the relationship between hotel and OTA is cooperative as well as competitive. In the decentralized decision-making model, they are more competitive than cooperative. Their purposes are to maximize their own profits. In reality, hotel can choose whether to inform the price of HA or not, for HA is competing with OTA. Uninformed of the prices in HA, OTA can predict the range of price on HA by the star-rated and room type of the hotel but it cannot know the exact price. Therefore, this section examines the pricing equilibrium between the hotel and OTA under two types of games, namely, the Bertrand and Stackelberg games. For the Bertrand game, both of the participants regard price as a decision variable; the hotel and OTA are uncooperative. For the Stackelberg game, the participants are divided into two roles, the leader and the follower. As a leader in tourism supply chain, the hotel will provide the policy to maximize its interests. As a follower, OTA accepts if profitable. By comparing the two models, we can understand how the behavior of hotel influences the pricing decisions.

5.1. Bertrand Game. In a Bertrand game, the procedure is as follows: keeping the wholesale price unchanged, the hotel determines HA's prices $p_{1}^{L}$ and $p_{1}^{H}$, so as to maximize profit $\pi_{1}$. Uninformed of the prices of HA, OTA decides prices $p_{2}^{L}$ and $p_{2}^{H}$, so as to maximize his profit $\pi_{2}$. Let $\left(p_{1}^{i}\right)^{B},\left(p_{2}^{i}\right)^{B}(i=$ $L, H)$ denote HA's and OTA's prices under a Bertrand model, respectively.

In the following, $L_{n}(n=1,2, \ldots, 5), s_{0}$, and $G_{m}(m=$ $1,2)$ are the threshold values and are given in Appendix $G$.

Proposition 3. There exist Bertrand equilibrium prices $\left(p_{1}^{i}\right)^{B *},\left(p_{2}^{i}\right)^{B *}(i=L, H)$, where

$$
\begin{aligned}
& \left(p_{1}^{i}\right)^{B *}=\frac{(1-\lambda \alpha) L_{1}+c \theta\left(b_{i}+\theta\right)}{(1-\lambda \alpha)\left[4\left(b_{i}+\theta\right)^{2}-\theta^{2}\right]}, \\
& \left(p_{2}^{i}\right)^{B *}=\frac{(1-\lambda \alpha) L_{2}+2 c\left(b_{i}+\theta\right)^{2}}{(1-\lambda \alpha)\left[4\left(b_{i}+\theta\right)^{2}-\theta^{2}\right]} .
\end{aligned}
$$


From Proposition 3, in the Bertrand model, the equilibrium prices for hotel and OTA are both affected by $\alpha$ and $\lambda$. With the increase of $\alpha$ or $\lambda$, both $\left(p_{1}^{i}\right)^{B *}$ and $\left(p_{2}^{i}\right)^{B *}$ will be higher. In other words, with higher uncertainty of room occupancy, the hotel and OTA tend to increase prices to protect their own profits.

Denote $c_{1}=(1-\lambda \alpha)\left(2 b_{L}+\theta-\beta\right) /\left(b_{L}+\theta\right)$ and $c_{2}=(1-$ $\lambda \alpha)\left(2 b_{H}+\theta-\beta\right) /\left(b_{H}+\theta\right)$; then $c_{1}>c_{2}$.

Corollary 4. $\left(p_{2}^{L}\right)^{B *}$ and $\left(p_{2}^{H}\right)^{B *}$ are increasing in $v .\left(p_{1}^{L}\right)^{B *}$ and $\left(p_{1}^{H}\right)^{B *}$ have the following relationships with respect to OTA's service:

(1) if $c^{\prime}(v)>c_{1}$, then $\partial\left(p_{1}^{L}\right)^{B *} / \partial v>0, \partial\left(p_{1}^{H}\right)^{B *} / \partial v>0$,

(2) if $c_{1}>c^{\prime}(v)>c_{2}$, then $\partial\left(p_{1}^{L}\right)^{B *} / \partial v<0, \partial\left(p_{1}^{H}\right)^{B *} / \partial v>$ 0 ,

(3) if $c^{\prime}(v)<c_{2}$, then $\partial\left(p_{1}^{L}\right)^{B *} / \partial v<0, \partial\left(p_{1}^{H}\right)^{B *} / \partial v<0$.

From Corollary 4, when OTA offers more effective services, its optimal prices will increase due to the increment in the cost. Marginal cost measures the input costs and the output value per unit. If the marginal cost is greater than $c_{1}$, then the costs of OTA to provide additional services are higher. So the equilibrium prices of HA will increase as the value added by OTA's services increases. When the marginal cost is between $c_{1}$ and $c_{2}$, HA's equilibrium price of economy rooms and the value added by OTA's service have a negative correlation, but HA's equilibrium price of luxury rooms would increase with the increment of $v$. In addition, when the marginal cost is less than $c_{2}$, the costs of OTA to provide additional service are lower. And the equilibrium prices of HA will decrease when $v$ increases.

Corollary 5. There exist threshold unit wholesale prices $w_{i}^{0}$, $w_{i}^{1}(i=L, H)$, such that

$$
\begin{aligned}
& \text { (1) }\left(p_{1}^{i}\right)^{*}<\left(p_{1}^{i}\right)^{B *}, \text { if } w_{i}>w_{i}^{0} ;\left(p_{1}^{i}\right)^{*}=\left(p_{1}^{i}\right)^{B *}, \text { if } w_{i}=w_{i}^{0} ; \\
&\left(p_{1}^{i}\right)^{*}>\left(p_{1}^{i}\right)^{B *}, \text { if } w_{i}<w_{i}^{0} . \\
& \text { (2) }\left(p_{2}^{i}\right)^{*}<\left(p_{2}^{i}\right)^{B *}, \text { if } w_{i}>w_{i}^{1} ;\left(p_{2}^{i}\right)^{*}=\left(p_{2}^{i}\right)^{B *} \text {, if } w_{i}=w_{i}^{1} ; \\
&\left(p_{2}^{i}\right)^{*}>\left(p_{2}^{i}\right)^{B *}, \text { if } w_{i}<w_{i}^{1},
\end{aligned}
$$

where

$$
\begin{aligned}
w_{i}^{0} & =\frac{L_{3}}{6 b_{i}\left(b_{i}+\theta\right)\left(b_{i}+2 \theta\right)}-\frac{c}{3(1-\lambda \alpha)} \\
w_{i}^{1} & =\frac{\theta\left[(1-\lambda \alpha) L_{4}-c b_{i} \theta\left(b_{i}+2 \theta\right)\right]}{2 b_{i}(1-\lambda \alpha)\left(b_{i}+2 \theta\right)\left(3 \theta^{2}+2 b_{i}^{2}+2 b_{i} \theta\right)} .
\end{aligned}
$$

From Proposition 1, it is easy to know that the equilibrium prices in the integrated system are not affected by the wholesale prices. However, from Proposition 3, in the Bertrand model, there is a positive correlation between the equilibrium prices and the wholesale prices. Corollary 5 shows that the equilibrium price of $\mathrm{HA}$ in the Bertrand game is higher than that in the integrated system if the wholesale price is greater than a certain critical point $\left(w_{i}^{0}\right)$. Additionally, if the wholesale price is greater than $w_{i}^{1}$, then the equilibrium price of OTA in Bertrand model will be higher than that in the integrated model.

Corollary 6. There exists a threshold unit wholesale price $w_{i}^{2}(i=L, H)$, such that if $w_{i}>w_{i}^{2}$, then $D_{i}^{*}>D_{i}^{B *}(i=L, H)$, where

$$
w_{i}^{2}=\frac{\theta\left[(1-\lambda \alpha)\left(v \beta+a_{i}\right)-b_{i} c\right]}{2 b_{i}(1-\lambda \alpha)\left(b_{i}+2 \theta\right)} .
$$

Corollary 6 shows that when the wholesale price is greater than $w_{i}^{2}$, the high price will lead to a lower demand in the Bertrand game. That is, the reservation amount of Bertrand model is less than that in the integrated model. The higher sale price in OTA results from the higher wholesale price. Thus, the above result is reasonable because travelers are price sensitive; especially for leisure travelers, the increase of price will bring the decline of reservation amount. When the relationship between the hotel and OTA is modeled as a Stackelberg game, the hotel can motivate customers to reserve rooms through a reasonable wholesale price. If the wholesale price is greater than the threshold, the sales volume in the centralized case is lower than that in the Bertrand case.

5.2. Stackelberg Game. In a Stackelberg game, the procedure is as follows: keeping the wholesale price unchanged, the hotel (as the leader) announces HA's prices $p_{1}^{L}$ and $p_{1}^{H}$ of two types of rooms, respectively, in order to maximize its profit $\pi_{1}$. In response to HA's prices, OTA (as the follower) determines prices $p_{2}^{L}$ and $p_{2}^{H}$ to maximize its profit $\pi_{2}$. Let $\left(p_{1}^{i}\right)^{S}$, $\left(p_{2}^{i}\right)^{S}(i=L, H)$ denote, respectively, HA's and OTA's prices under a Stackelberg game.

Proposition 7. The optimal prices are $\left(p_{1}^{i}\right)^{S *},\left(p_{2}^{i}\right)^{S *}(i=$ $L, H)$, and there exists a threshold unit wholesale price $w_{i}^{3}(i=$ $L, H)$, such that if $w_{i}>w_{i}^{3}$, then $\left(p_{1}^{i}\right)^{*}<\left(p_{1}^{i}\right)^{S *}$, where

$$
\begin{aligned}
\left(p_{1}^{i}\right)^{S *}=\frac{(1-\lambda \alpha)\left(L_{1}-w_{i} \theta^{2}-w_{i} b_{i} \theta\right)+c \theta\left(b_{i}+\theta\right)}{(1-\lambda \alpha)\left[4\left(b_{i}+\theta\right)^{2}-2 \theta^{2}\right]} & \\
\left(p_{2}^{i}\right)^{S *} & \\
= & \frac{\theta\left(p_{1}^{i}\right)^{S *}+(1-s) a_{i}+v(\theta+\beta)+w_{i}\left(b_{i}+\theta\right)}{2\left(b_{i}+\theta\right)} \\
& +\frac{c}{2(1-\lambda \alpha)}, \\
w_{i}^{3} \quad & \frac{b_{i} v \beta+a b_{i}+\theta v b_{i}+a_{i} \theta+\theta v \beta-a_{i} b_{i} s}{2 b_{i}\left(b_{i}+2 \theta\right)} \\
& -\frac{c}{2(1-\lambda \alpha)} .
\end{aligned}
$$

Similar to the Bertrand competition, the equilibrium prices in Stackelberg game will increase with the increase of 
the return expense proportion $(\alpha)$ or the cancellations and no-show proportion $(\lambda)$.

From Proposition 7, we can see that the Stackelberg model is similar to the Bertrand model that the equilibrium prices would increase with the increase of wholesale prices. Furthermore, when the wholesale price is greater than $w_{i}^{3}$, the equilibrium price of HA in Stackelberg model will be higher than that in the integrated model.

In the Stackelberg game, if OTA offers more effective services, the equilibrium prices of OTA would increase accordingly. The relationship between the Stackelberg equilibrium prices and $v$ is similar to that in the Bertrand model.

5.3. Contrastive Analysis of Bertrand and Stackelberg Games. Based on the equilibrium prices obtained in the previous section, we in this section compare the equilibrium prices and optimal profit under Bertrand and Stackelberg games.

Corollary 8. There exists a threshold unit wholesale price $w_{i}^{4}(i=L, H)$, such that

(1) $\left(p_{1}^{i}\right)^{B *}>\left(p_{1}^{i}\right)^{S *}$ and $\left(p_{2}^{i}\right)^{B *}>\left(p_{2}^{i}\right)^{S *}$ if $w_{i}>w_{i}^{4}$,

(2) $\left(p_{1}^{i}\right)^{B *}=\left(p_{1}^{i}\right)^{S *}$ and $\left(p_{2}^{i}\right)^{B *}=\left(p_{2}^{i}\right)^{S *}$ if $w_{i}=w_{i}^{4}$,

(3) $\left(p_{1}^{i}\right)^{B *}<\left(p_{1}^{i}\right)^{S *}$ and $\left(p_{2}^{i}\right)^{B *}<\left(p_{2}^{i}\right)^{S *}$ if $w_{i}<w_{i}^{4}$,

where

$$
w_{i}^{4}=\frac{\theta\left[(1-\lambda \alpha) L_{5}+c \theta\left(b_{i}+\theta\right)\right]}{4 b_{i}(1-\lambda \alpha)\left(b_{i}+\theta\right)\left(b_{i}+2 \theta\right)} .
$$

Corollary 8 compares the equilibrium prices under the Bertrand and Stackelberg game with respect to the wholesale price. It shows that if the wholesale price is greater than $w_{i}^{4}$, the pricing equilibrium under the Bertrand is higher than that under the Stackelberg game. Conversely, the pricing equilibrium is lower if the wholesale price is less than $w_{i}^{4}$.

In the decentralized case, both the manufacturer and the retailer want to maximize their profit. A high wholesale price could be passed on to customers. Therefore, the above results exist. In addition, how to share the profit between the manufacturer and the retailer depends on their bargaining powers.

Corollary 9. If $w_{i} \neq w_{i}^{4}(i=L, H)$, then $\pi_{1}^{S *}>\pi_{1}^{B *}$. OTA's profit has the following relationship with respect to $w_{i}^{4}$ :

(1) $\pi_{2}^{B *}>\pi_{2}^{S *}$ if $w_{L}>w_{L}^{4}$ and $w_{H}>w_{H}^{4}$,

(2) $\pi_{2}^{B *}=\pi_{2}^{S *}$ if $w_{L}=w_{L}^{4}$ and $w_{H}=w_{H}^{4}$,

(3) $\pi_{2}^{B *}<\pi_{2}^{S *}$ if $w_{L}<w_{L}^{4}$ and $w_{H}<w_{H}^{4}$.

The hotel is the leader in Stackelberg game and can always benefit from it except for the critical point $w_{i}^{4}$. Compared with the Bertrand game, the hotel can get higher profits in Stackelberg game when the wholesale price is not equal to $w_{i}^{4}$. Therefore, in decentralized decision-making model, the hotel will be more inclined to be the price leader in order to ensure that it can achieve higher profits.

Corollary 9 indicates that the Stackelberg model is superior to the Bertrand model when the wholesale price is less than the critical point $w_{i}^{4}$. Not only the hotel but also OTA can gain more profit from the Stackelberg game. Though OTA is a follower in Stackelberg game, the profit will not be reduced because the lower wholesale prices can compensate for the loss of profit caused by the opening of HA channel. Consequently, the hotel should play the role of the price leader in the supply chain and develop reasonable wholesale prices to achieve optimization of the whole supply chain profit while optimizing its own profit.

Corollary 10. Under either Bertrand or Stackelberg equilibrium channel prices, there exists optimal wholesale price $w_{i}^{*}(i=L, H)$ that maximizes the total equilibrium channel profit, where $w_{i}^{*}=G_{1} / G_{2}$.

According to Corollary 10, there exists optimal wholesale price $w_{i}^{*}(i=L, H)$ that maximizes the total equilibrium channel profit under either Bertrand or Stackelberg game. The optimal wholesale price will optimize the decentralized decision-making supply chain. Meanwhile, both the hotel and the OTA can benefit from the optimal wholesale price. Therefore, the reasonable wholesale price can help promote mutual cooperation and communication between the supply chain members.

\subsection{Contrastive Analysis of Two Channels in the Supply Chain}

Corollary 11. There exists a threshold unit market share of HA in the tourism dual-channel supply chain $\left(s_{0}\right)$, such that when $s>s_{0}$, the hotel's profit from HA is higher than that from OTA.

Keeping the wholesale prices and sales prices unchanged, when the market share of HA in the tourism dual-channel supply chain exceeds a certain value $s_{0}$, the hotel's profit from HA is higher than that from OTA. The result is suitable for the integrated system, Bertrand and Stackelberg games. From the perspective of hotel's revenue, the hotel should explore the channel for direct selling actively. Also, the hotel can strengthen the promotion of HA channel to improve the customer's understanding and preference for the HA channel. But the premise is that the profit growth from the promotion can compensate for the cost. According to the statistical data from the hotel price competitiveness analysis report in the first half of 2012, we know that the booking cost from direct selling channel is about 1 dollar per night, but that from OTA is about 10 dollars per night. Booking cost can be reduced by $46 \%$ if the direct selling level is doubled. Then improving the market share of direct selling will greatly reduce the cost. More comparisons of different channel's profits in each model can be found in part of numerical analysis.

\section{Overbooking}

This section extends to consider the overbooking case. Regarding overbooking, in the hospitality industry, the common practice is that the hotel upgrades the room type or transfers customers to other hotels nearby that have the same level and same type. In airline industry, if customers are denied boarding after arriving at the airport, the airline will 
provide a free upgrade, endorse the ticket, or provide compensation for the customers according to specific situation. Compared to the hotels, the airlines cannot transfer customers to other companies. The air ticket alteration will usually disrupt customers' traveling schedule. Though the overbooking by airlines has been well studied in the literature, our research is new in the hospitality industry by considering the overbooking with/without room transfer, with the hope that certain implications can be enlightened to the hotel managers.

The hotel wants to increase the occupancy rates to increase the profits through overbooking. However, overbooking will lead to the risk that the actual occupancy amount is greater than the number of hotel rooms. Therefore, the hotel has to provide compensation to travelers who cannot check in, that is, overbooking cost. The greater the numbers of overbooking, the less the probability of room vacancy, but at the same time travelers are more likely to be refused by the hotel. Therefore, the hotel must balance between the vacancy lost and the overbooking costs. We develop a model to analyze the overbooking choice.

In reality, the OTA is always a crucial partner of hotels for it can attract a large number of customers for hotels and improve their occupancy rates [36]. Spontaneously, the OTA plays an increasingly significant role in the distribution systems of hotels $[5,7]$. By contrast, the HA mainly provides a platform for individual guest. Compared with individual customers, hotel pays more attention to the long-term cooperation relationship with the OTA. Therefore, in our model, we assume that when the market demand is greater than the supply and the hotel does not carry out overbooking, the hotel would give priority to customers who are booking from OTA.

6.1. Without Room Transfer. Here, we consider the case with no room transfer. When the actual occupancy amount exceeds the total quantity of rooms, the hotel does not arrange other alternative accommodation for the customers who cannot check in. But the hotel must pay the loss of goodwill cost. Suppose that the overbooking quantity of economy and luxury rooms is $\Delta C_{L}$ and $\Delta C_{H}$ and the overbooking cost is $c_{L}$ and $c_{H}$, respectively.

We discuss economy rooms' overbooking. The actual occupancy can be either of the following two cases: (1) when $Q_{L}<D_{1}^{L}+D_{2}^{L} \leq Q_{L}+\Delta C_{L}$, the reservation amount of rooms is $D_{1}^{L}+D_{2}^{L}$, so the actual occupancy amount is $\left(D_{1}^{L}+\right.$ $\left.D_{2}^{L}\right)(1-\lambda)$; (2) when $D_{1}^{L}+D_{2}^{L}>Q_{L}+\Delta C_{L}$, the reservation amount is $Q_{L}+\Delta C_{L}$; then the actual occupancy amount is $\left(Q_{L}+\Delta C_{L}\right)(1-\lambda)$. Therefore, if $\left(Q_{L}+\Delta C_{L}\right)(1-\lambda) \leq Q_{L}$, that is, $\Delta C_{L} \leq \lambda Q_{L} /(1-\lambda)$, the profit of hotel is

$$
\pi_{11}^{L}=(1-\lambda \alpha)\left[p_{1}^{L}\left(Q_{L}+\Delta C_{L}-D_{2}^{L}\right)+w_{L} D_{2}^{L}\right] .
$$

If $\left(Q_{L}+\Delta C_{L}\right)(1-\lambda) \geq Q_{L}$, that is, $\Delta C_{L} \geq \lambda Q_{L} /(1-\lambda)$, the economy rooms' actual occupancy amount exceeds the economy rooms' number in the hotel, so the hotel must pay the overbooking cost; then the profit of hotel is

$$
\begin{aligned}
\pi_{12}^{L}= & (1-\lambda \alpha)\left[p_{1}^{L}\left(Q_{L}+\Delta C_{L}-D_{2}^{L}\right)+w_{L} D_{2}^{L}\right] \\
& -\left(p_{1}^{L}+c_{L}\right)\left[\left(Q_{L}+\Delta C_{L}\right)(1-\lambda)-Q_{L}\right] .
\end{aligned}
$$

Proposition 12. Without considering rooms' transfer, the optimal overbooking quantity of economy rooms and luxury rooms is

$$
\Delta C_{i}^{*}=\frac{\lambda}{1-\lambda} Q_{i}, \quad i=L, H .
$$

From Proposition 12, we know that the higher the proportion of customer cancellations and no-show is, the larger the optimal overbooking quantity of the hotel will be. With the increase of $\alpha$, the penalty that customers need to pay for their cancellation or no-show decreases. Two following extreme situations are considered. When $\alpha=1$, the hotel will return all the guarantee fee in case of customers' cancellation or noshow. That is the same as the hotel does not charge customers any guarantee fee when customers book the rooms. Under such circumstances, customers can book rooms for several days firstly; after they identify a specific itinerary, they can cancel the extra rooms for they do not suffer any loss. It is no doubt that such regulation will increase the cancellation and no-show rate. On the other hand, if $\alpha=1$, all the guarantee fee will not be returned after cancellation or no-show. In this case, customers need to reserve a room cautiously. If it is not necessary, customers will not choose cancellation or no-show because the penalty cost is too high. Such policy will reduce the cancellation and no-show rate. Spontaneously, to some extent, $\alpha$ and $\lambda$ are positive correlation. When the hotel increases proportion $\alpha$, it would like to increase the overbooking quantity, so as to increase the actual occupancy rate. Nowadays, the time-limited orders are widely used among hotels. Such regulation cannot only reduce customers' loss for the change of schedule but also help the hotel confirm the orders so as to handle the overbooking phenomenon in advance.

In addition, the risk of overbooking the economy rooms is relatively lower than the luxury rooms. Compared to economic rooms, it is more difficult for the hotel to find alternative luxury rooms to satisfy the customers. Naturally, overbooking cost of luxury room is higher. For instance, if economy rooms are overbooked, the hotel can transfer the customers to luxury rooms and the customers are willing to accept. By contrast, if luxury rooms are overbooked, customers are not willing to accept the adjustment from luxury rooms to economic rooms. This implies that the hotel has to pay a higher default cost. Therefore, the hotel should be more careful to choose the overbooking quantity of luxury rooms.

6.2. With Room Transfer. The following discusses the case with room transfer. Firstly, when the economy rooms are insufficient and luxury rooms have a surplus, customers can check in the hotel's luxury rooms with the price of economy rooms. Customers spend the same money and can enjoy better service, so they are willing to accept this adjustment. Secondly, when the luxury rooms' actual occupancy amount exceeds the number of luxury rooms in the hotel, the hotel usually transfers customers to other hotels nearby that have the same level and same type because the customers who book luxury room have a high requirement. Customers can enjoy the same service, so they are willing to accept this transfer. However, the hotel's credibility in customers' mind will be 
damaged and it must pay the additional costs. Thirdly, if both the economy rooms and luxury rooms are unable to meet the demand, the hotel usually transfers the customers who cannot check in to other hotels. Note that when $D_{1}^{i}+D_{2}^{i}>Q_{i}$, $i=L, H$, if the hotel does not overbook, its profit is

$$
\begin{aligned}
& \pi_{111}=(1-\lambda \alpha)\left[p_{1}^{L}\left(Q_{L}-D_{2}^{L}\right)+p_{1}^{H}\left(Q_{H}-D_{2}^{H}\right)\right. \\
& \left.+w_{L} D_{2}^{L}+w_{H} D_{2}^{H}\right]
\end{aligned}
$$

Proposition 13. With room transfer, there exists threshold unit overbooking cost $c_{i 0}$, such that if $c_{i}<c_{i 0}$, then overbooking is profitable for the hotel, where

$$
c_{i 0}=\frac{(1-\lambda \alpha) p_{1}^{i}}{1-\lambda}, \quad i=L, H
$$

From Propositions 12 and 13, we conclude that the hotel should control the overbooking quantity in a certain range to prevent lacking of rooms. If the overbooking proportion is too large, then the hotel may face a loss. Only when the overbooking cost is low, the hotel can obtain additional profit. Otherwise, if the overbooking cost exceeds a certain value, the hotel's profit would be lower when it carries out overbooking. As the market demand increases, the supply is close to saturation, and then the overbooking costs will be higher. Therefore, when the market demand is excessive, the hotel should strictly control the proportion of overbooking. In addition, if the number of hotels that have the same level and type in the same region is little, that is, the possibility to transfer customer is small, then the hotel should lower the proportion of overbooking.

The proportion of overbooking depends on the proportion of customer cancellations and no-show as well as the total number of hotel rooms, so the hotel can analyze the historical data to develop an appropriate overbooking proportion, so as to maximize the hotel's expected profit.

Proposition 14. When the economy rooms and luxury rooms are both overbooked, the optimal centralized prices are as follows: $i=L, H$,

$$
\begin{aligned}
& p_{14}^{i *}=p_{1}^{i *}+\frac{c_{u}^{i}(1-\lambda)}{2(1-\lambda \alpha)}, \\
& p_{24}^{i *}=p_{2}^{i *}+\frac{c_{u}^{i}(1-\lambda)}{2(1-\lambda \alpha)} .
\end{aligned}
$$

Bertrand and Stackelberg prices are as follows:

$$
\begin{aligned}
& \left(p_{14}^{i}\right)^{B *}=\left(p_{1}^{i}\right)^{B *}+\frac{2 c_{u}^{i} b_{i}\left(b_{i}+\theta\right)(1-\lambda)}{(1-\lambda \alpha)\left[4\left(b_{i}+\theta\right)^{2}-\theta^{2}\right]}, \\
& \left(p_{24}^{i}\right)^{B *}=\left(p_{2}^{i}\right)^{B *}+\frac{\theta c_{u}^{i} b_{i}(1-\lambda)}{(1-\lambda \alpha)\left[4\left(b_{i}+\theta\right)^{2}-\theta^{2}\right]}, \\
& \left(p_{14}^{i}\right)^{S *}=\left(p_{1}^{i}\right)^{S *}+\frac{c_{u}^{i} b_{i}\left(2 b_{i}+3 \theta\right)(1-\lambda)}{(1-\lambda \alpha)\left[4\left(b_{i}+\theta\right)^{2}-2 \theta^{2}\right]},
\end{aligned}
$$

$$
\begin{aligned}
& \left(p_{24}^{i}\right)^{S *} \\
& =\frac{\theta\left(p_{14}^{i}\right)^{S *}+(1-s) a_{i}+v(\theta+\beta)+w_{i}\left(b_{i}+\theta\right)}{2\left(b_{i}+\theta\right)} \\
& \quad+\frac{c}{2(1-\lambda \alpha)} .
\end{aligned}
$$

For the hotel, the premise to overbook rooms is that the market demand is greater than the supply. When the hotel faces the risk of overbooking, the equilibrium prices in both centralized and decentralized decision-making supply chain will improve. In the busy season, in order to reduce the risk of overbooking, the hotel would increase the prices and the increment will increase as the transfer cost increases. From (16) and (17) we can know that the increment in centralized decision-making model is the greatest and that in Bertrand game is the smallest.

\section{Numerical Analysis}

In this section, we do some numerical experiment to gain more insights. According to the China Hotel Sales Channel Report by I-Research (http://report.iresearch.cn/report/ $201303 / 1892 . s h t m l$ ), there are $38.1 \%$ of the hotels that are suitable for high-end travelers and $61.9 \%$ of the hotels that are suitable for low-end travelers. Therefore, this part assumes that the proportion of the economical rooms and the luxury rooms is $4: 6$; that is, $a_{L}=0.6 a, a_{H}=0.4 a$. Other parameter settings are made as follows: $a=600, s=0.5$, and $b_{L}=0.6$; $b_{H}=0.2 ; \beta=\theta=0.5 ; \eta=0.04 ; \alpha=0.8 ; \lambda=0.1 ; w_{i}=0.5 p_{1}^{i}$ $(i=L, H)$. In the following we investigate the impact of $v$ on the optimal prices and profits.

When $v=0$, that is, the OTA does not offer any service, then the optimal prices of $\mathrm{HA}$ are equal to the prices of OTA. Since $b_{L}>\beta>b_{H}$, then the market of economy rooms is service-oriented, while the market of luxury rooms is price-oriented. From Figure 2, we can know that when OTA offers more services, OTA's optimal price will be increased accordingly. It is reasonable that if $v$ increases, the cost of OTA will also definitely increase. With the increase of $v, p_{1}^{L *}$ will decline slowly, while $p_{1}^{H *}$ will increase.

The OTA's profit status becomes better with the improvement of its price. But as the $v$ increases, the cost of OTA will also definitely increase. When $v$ is equal to 27 , then the profit of OTA is the highest. If $v$ is larger, then the high costs will reduce the profits of OTA. When $v$ is equal to 34 , the profit of the whole supply chain is the highest. So, from the perspective of the supply chain, $v$ is expected to be 34 rather than 27 . Similarly for the integrated system, the profit of the OTA also rises first and then declines with the increase of $v$. After calculation we can get that when $v=27$, both $\pi_{2}^{B *}$ and $\pi_{2}^{S *}$ will be the highest. From Figures 3 and 4, we know that the OTA would tend to offer service that valued 27 , so as to maximize its own profit.

After calculation we can conclude that when $v=34$, then $\pi^{B *}$ is highest; when $v=35$, then $\pi^{S *}$ is highest (Figure 5). 


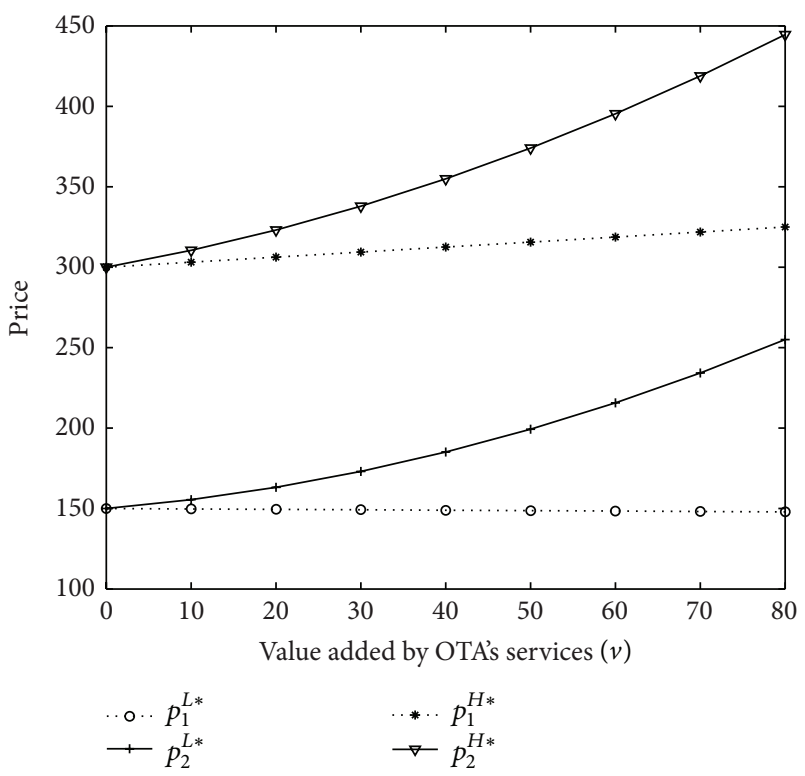

FIGURE 2: Equilibrium prices in the integrated system.

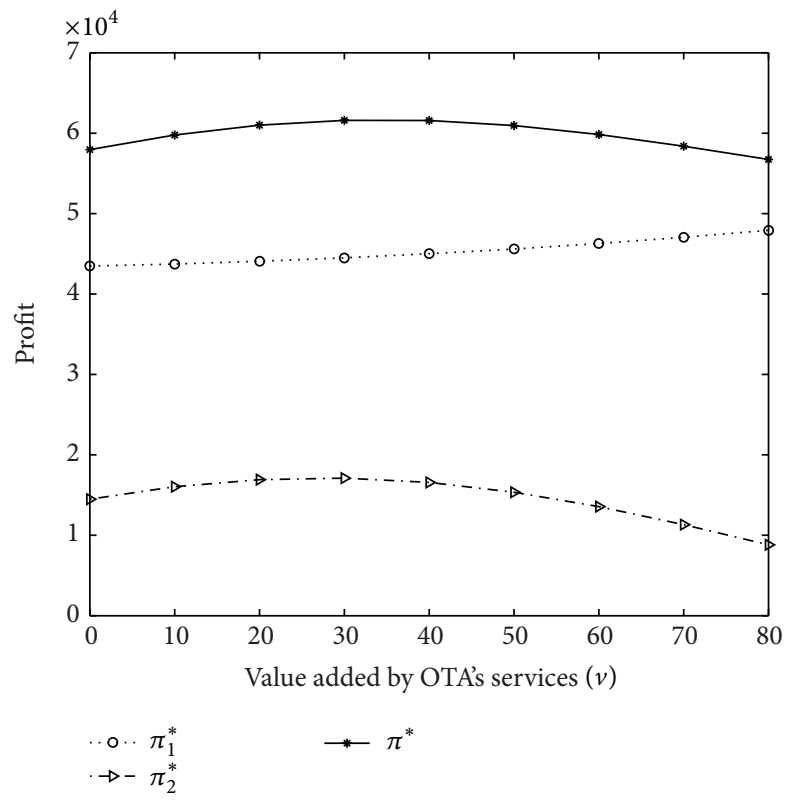

FIGURE 3: Profits in the integrated system.

From the perspective of the supply chain, the OTA is expected to offer more services. Despite the rising cost of OTA will lower its profit, the hotel can lower the wholesale prices to coordinate the distribution of profits, so as to achieve a winwin situation.

In the following, we focus on the comparison of different channel's profit in each model. Figure 6 depicts the curves of the total profits of the HA/OTA channels in the integrated system with respect to $v$. Figure 7 draws the curves of the different channels' profits under both Bertrand and Stackelberg game. The profit of the HA channel refers to the profit that the hotel derived from the HA channel. The profit of the OTA

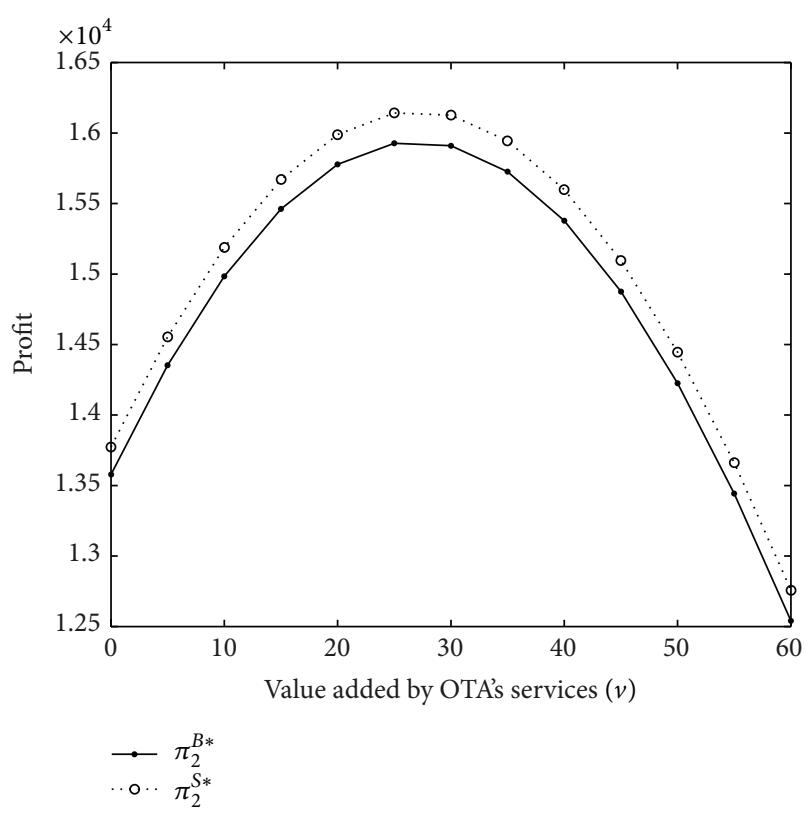

FIgURE 4: OTA's profits under two games.

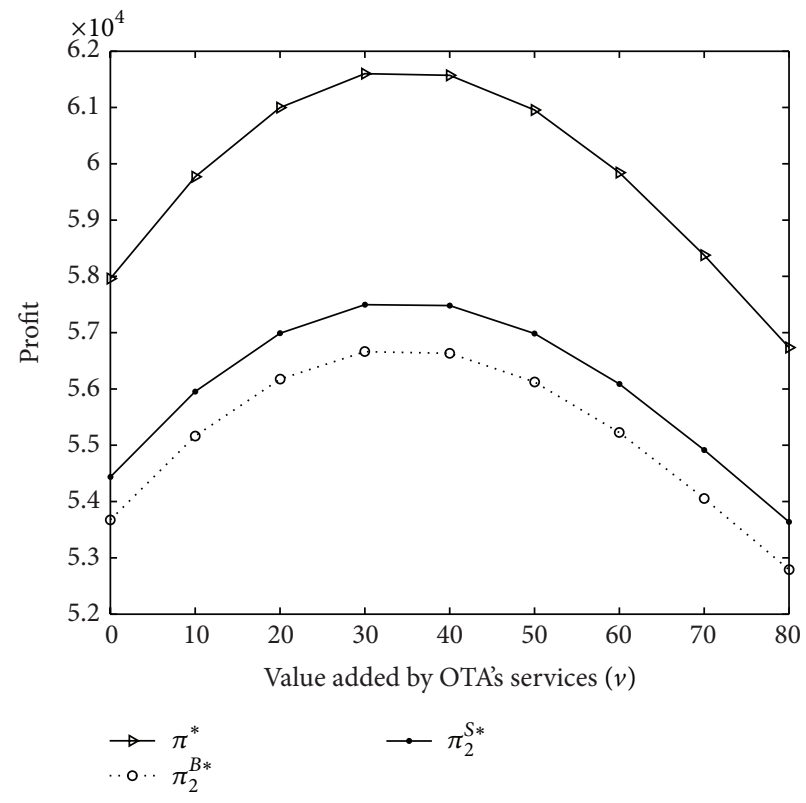

FIGURE 5: The profit comparison.

channel involves the OTA's profit and the hotel's profit gained from the OTA channel.

As shown in Figures 6 and 7, with the increase of $v$, the profit of the OTA channel will increase first and will then decrease. This indicates that a high level of service by OTA will be detrimental to the channel profit. That is because a high level of service will bring a high cost undoubtedly. For the integrated model and Bertrand game model, this disadvantage is more evident. The OTA's service can motivate the actual purchase behavior of customers in the OTA channel. When $v$ is relatively lower, the additional profits from OTA's 


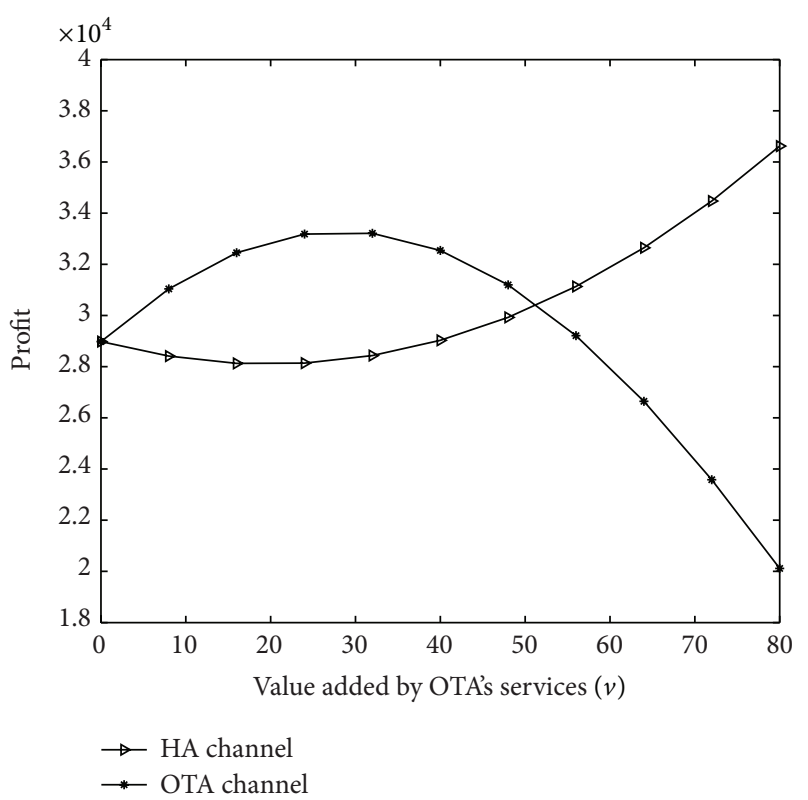

Figure 6: Channel profits in the integrated system.

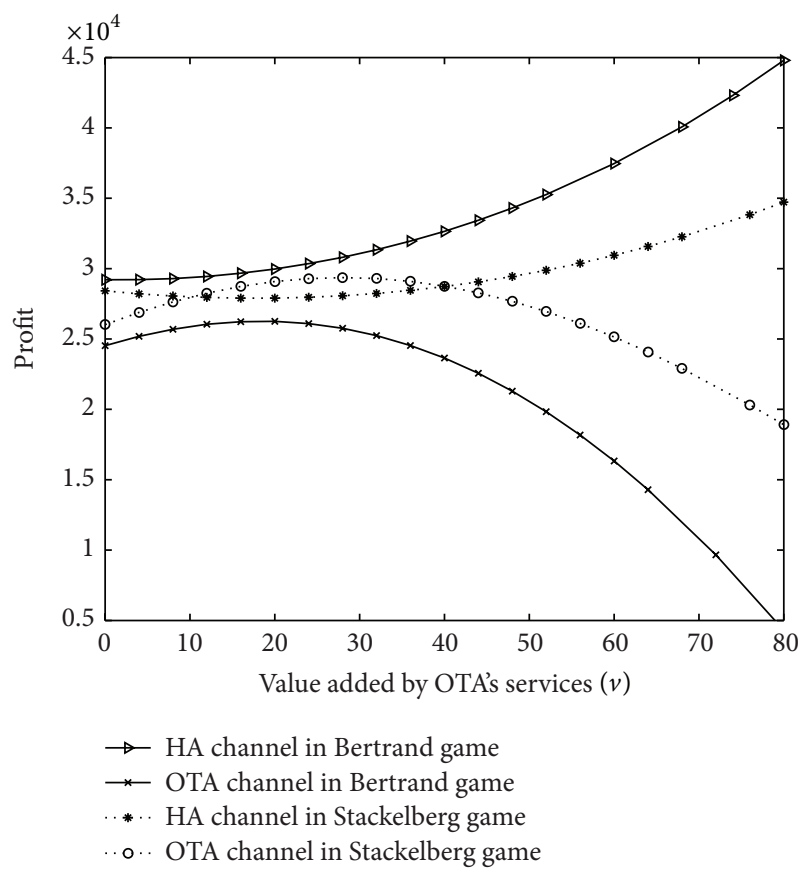

FIGURE 7: Channel profits in two games.

service are enough to compensate for the cost. In this case, the hotel and the OTA can get more profit from providing the service. However, when $v$ is high, the additional profits from OTA's service cannot make up for the high cost. In such phenomenon, the OTA should not increase investment in service.

For both integrated model and Bertrand game model, with the increase of $v$, the profit of the HA channel will decrease first and will then increase, while in the Stackelberg game model, the profit of the HA channel will always increase with $v$. With Figure 2 we can know that when OTA provides more additional services, it tends to increase its price. Some of the customers will turn to reserve rooms from the HA because of the excessively high price in OTA. As a result, the hotel can gain more profits from the HA channel.

\section{Conclusion}

With the development of e-commerce, the providers of tourism products are more inclined to build dual-channels. In this paper, we consider the direct selling channel of HA and the traditional retail channel of OTA from the perspective of tourism supply chain. We develop a two-echelon tourism supply chain model involving one hotel and one OTA where the OTA provides related service. Customers will be refunded partially in case of cancelation or no-show. We investigate the optimal pricing strategies under several common cases. The integrated operation and the decentralized operation based on Bertrand and Stackelberg games are studied and corresponding equilibrium pricing policies are obtained.

Our findings demonstrate that the hotel plays a crucial role in optimizing the benefits of supply chain. Considering the overall profit of the supply chain, the hotel should act as a leader in dual-channel supply chain and formulate reasonable wholesale prices to improve the cooperative enthusiasm of OTA, so as to achieve optimization of the whole supply chain. A lower wholesale price can help reduce OTA's loss of profit because of the opening of HA channel. In addition, we consider the overbooking of the hotel and obtain the optimal overbooking quantity. We conclude that the hotel can always obtain higher profits when the overbooking proportion is controlled within a certain range. Otherwise, if the overbooking proportion is too high, the hotel can get extra profits only when the overbooking cost is lower than a certain value.

The contribution of this paper is that we extend tourism supply chain to the dual-channel structure in which the hotel opens its direct channel to sell tourism products. And the extant literature only refers to the single channel. In addition, we realize that customer cancellations and no-show occur frequently in hotel industry. Thus, we develop the game models based on such phenomenon. At last, we derive the conditions under which the hotel dominant case is profitable for both the supply chain members. Our results can provide hotels and OTAs with some new managerial insights under the dual-channel environment.

This research can be extended in several directions in future work. For example, in this paper we assume that all information is known to the hotel and OTA. However, some information could be asymmetric (e.g., see Chen [37]). Thus, we can explore the Bayesian equilibrium under asymmetric information settings. Secondly, the assumption of linear demand is a limitation of this paper. We can further study the dynamic pricing in tourism dual-channel supply chain.

\section{Appendix}

\section{A. Proof of Corollary 8}

First we set $\left(p_{1}^{L}\right)^{B *}>\left(p_{1}^{L}\right)^{S *}$, which can be expressed as 


$$
\begin{gathered}
\frac{(1-\lambda \alpha)\left(\theta a_{L}+\theta s a_{L}+2 b_{L} s a_{L}+\theta v \beta+3 w_{L} \theta^{2}+3 w_{L} b_{L} \theta-\theta^{2} v-2 \theta b_{L} v\right)+c \theta\left(b_{L}+\theta\right)}{(1-\lambda \alpha)\left[4\left(b_{L}+\theta\right)^{2}-\theta^{2}\right]} \\
>\frac{(1-\lambda \alpha)\left(\theta a_{L}+\theta s a_{L}+2 b_{L} s a_{L}+\theta v \beta+2 w_{L} \theta^{2}+2 w_{L} b_{L} \theta-\theta^{2} v-2 \theta b_{L} v\right)+c \theta\left(b_{L}+\theta\right)}{(1-\lambda \alpha)\left[4\left(b_{L}+\theta\right)^{2}-2 \theta^{2}\right]} .
\end{gathered}
$$

The above equation can be simplified as

$$
w_{L}>\frac{\theta\left[(1-\lambda \alpha)\left(\theta a_{L}+\theta s a_{L}+2 b_{L} s a_{L}+\theta v \beta-\theta^{2} v-2 \theta b_{L} v\right)+c \theta\left(b_{L}+\theta\right)\right]}{4 b_{L}(1-\lambda \alpha)\left(b_{L}+\theta\right)\left(b_{L}+2 \theta\right)} .
$$

So we can get Corollary 8 .

\section{B. Proof of Corollary 9}

$$
\text { If }\left(p_{1}^{i}\right)^{S *}>\left(p_{1}^{i}\right)^{B *} \text {, then }
$$

$$
\begin{aligned}
& (1-\lambda \alpha)\left(\theta a_{i}+\theta s a_{i}+2 b_{i} s a_{i}+\theta v \beta+2 w_{i} \theta^{2}+2 w_{i} b_{i} \theta-\theta^{2} v-2 \theta b_{i} v\right)+c \theta\left(b_{i}+\theta\right) \\
& \quad-(1-\lambda \alpha)\left(\left(p_{1}^{i}\right)^{S *}+\left(p_{1}^{i}\right)^{B *}\right)\left[2\left(b_{i}+\theta\right)^{2}-\theta^{2}\right]>0 \\
& \pi_{1}^{S *}-\pi_{1}^{B *}=\frac{(1-\lambda \alpha)\left(\theta a_{L}+\theta s a_{L}+2 b_{L} s a_{L}+\theta v \beta+2 w_{L} \theta^{2}+2 w_{L} b_{L} \theta-\theta^{2} v-2 \theta b_{L} v\right)+c \theta\left(b_{L}+\theta\right)}{2\left(b_{L}+\theta\right)}\left(\left(p_{1}^{L}\right)^{S *}-\left(p_{1}^{L}\right)^{B *}\right) \\
& \quad+\frac{(1-\lambda \alpha)\left(\theta a_{H}+\theta s a_{H}+2 b_{H} s a_{H}+\theta v \beta+2 w_{H} \theta^{2}+2 w_{H} b_{H} \theta-\theta^{2} v-2 \theta b_{H} v\right)+c \theta\left(b_{H}+\theta\right)}{2\left(b_{H}+\theta\right)}\left(\left(p_{1}^{H}\right)^{S *}-\left(p_{1}^{H}\right)^{B *}\right) \\
& \quad-(1-\lambda \alpha) \frac{2\left(b_{L}+\theta\right)^{2}-\theta^{2}}{2\left(b_{L}+\theta\right)}\left[\left(\left(p_{1}^{L}\right)^{S *}\right)^{2}-\left(\left(p_{1}^{L}\right)^{B *}\right)^{2}\right]-(1-\lambda \alpha) \frac{2\left(b_{H}+\theta\right)^{2}-\theta^{2}}{2\left(b_{H}+\theta\right)}\left[\left(\left(p_{1}^{H}\right)^{S *}\right)^{2}-\left(\left(p_{1}^{H}\right)^{B *}\right)^{2}\right]>0
\end{aligned}
$$

If $\left(p_{1}^{L}\right)^{S *}<\left(p_{1}^{L}\right)^{B *}$ and $\left(p_{1}^{H}\right)^{S *}<\left(p_{1}^{H}\right)^{B *}$, we can prove $\pi_{1}^{S *}>\pi_{1}^{B *}$ similarly.

From Propositions 3 and 7 with (3), we obtain that

$$
\begin{aligned}
\pi_{2}^{B *}-\pi_{2}^{S *}=\frac{\theta}{4\left(b_{L}+\theta\right)}\{2(1-\lambda \alpha) \\
\cdot\left[(1-s) a_{L}+v(\beta+\theta)-w_{L}\left(b_{L}+\theta\right)\right] \\
\left.-2 c\left(b_{L}+\theta\right)+\theta(1-\lambda \alpha)\left(\left(p_{1}^{L}\right)^{B *}+\left(p_{1}^{L}\right)^{S *}\right)\right\} \\
\cdot\left(\left(p_{1}^{L}\right)^{B *}-\left(p_{1}^{L}\right)^{S *}\right)+\frac{\theta}{4\left(b_{H}+\theta\right)}\{2(1-\lambda \alpha) \\
\cdot\left[(1-s) a_{H}+v(\beta+\theta)-w\left(b_{H}+\theta\right)\right] \\
\left.-2 c\left(b_{H}+\theta\right)+\theta(1-\lambda \alpha)\left(\left(p_{1}^{H}\right)^{B *}+\left(p_{1}^{H}\right)^{S *}\right)\right\} \\
\cdot\left(\left(p_{1}^{H}\right)^{B *}-\left(p_{1}^{H}\right)^{S *}\right) .
\end{aligned}
$$

\section{Note that}

$$
D_{2}^{i}=\left[(1-s) a_{i}-b_{i} p_{2}^{i}\right]+\beta v+\theta\left(p_{1}^{i}+v-p_{2}^{i}\right)>0,
$$

so we show that

$$
\begin{aligned}
& 2(1-\lambda \alpha)\left[(1-s) a_{i}+v(\beta+\theta)-w_{i}\left(b_{i}+\theta\right)\right] \\
& \quad-2 c\left(b_{i}+\theta\right)+\theta(1-\lambda \alpha)\left(\left(p_{1}^{i}\right)^{B *}+\left(p_{1}^{i}\right)^{S *}\right)
\end{aligned}
$$
$>0$.

Thus, we have the following:

(1) $\pi_{2}^{B *}>\pi_{2}^{S *}$, if $\left(p_{1}^{L}\right)^{B *}>\left(p_{1}^{L}\right)^{S *}$ and $\left(p_{1}^{H}\right)^{B *}>\left(p_{1}^{H}\right)^{S *}$.

(2) $\pi_{2}^{B *}=\pi_{2}^{S *}$, if $\left(p_{1}^{L}\right)^{B *}=\left(p_{1}^{L}\right)^{S *}$ and $\left(p_{1}^{H}\right)^{B *}=\left(p_{1}^{H}\right)^{S *}$.

(3) $\pi_{2}^{B *}<\pi_{2}^{S *}$, if $\left(p_{1}^{L}\right)^{B *}<\left(p_{1}^{L}\right)^{S *}$ and $\left(p_{1}^{H}\right)^{B *}<\left(p_{1}^{H}\right)^{S *}$.

Combined with Corollary 8, the proposition is proved. 


\section{Proof of Corollary 10}

The profit of hotel from the economy rooms is as follows:

$\pi_{L}$

$=\left[(1-\lambda \alpha)\left(s a_{L}-\theta v\right)-c \theta\right] p_{1}^{L}$

$+\left[(1-\lambda \alpha)\left(a_{L}-s a_{L}+\beta v+\theta v\right)+c\left(b_{L}+\theta\right)\right] p_{2}^{L}$

$$
\begin{aligned}
\left(B_{1}^{L}\right)^{B} & =\frac{3 \theta\left(b_{L}+\theta\right)}{4\left(b_{L}+\theta\right)^{2}-\theta^{2}}, \\
\left(B_{1}^{L}\right)^{S} & =\frac{\theta\left(b_{L}+\theta\right)}{2\left(b_{L}+\theta\right)^{2}-\theta^{2}} . \\
\left(B_{2}^{L}\right)^{B(S)} & =\frac{\theta}{2\left(b_{L}+\theta\right)}\left(B_{1}^{L}\right)^{B(S)}+\frac{1}{2}, \\
\left(A_{1}^{L}\right)^{B} & =\frac{(1-\lambda \alpha)\left(\theta a_{L}+\theta s a_{L}+2 b_{L} s a_{L}+\theta v \beta-\theta^{2} v-2 \theta b_{L} v\right)+c \theta\left(b_{L}+\theta\right)}{(1-\lambda \alpha)\left[4\left(b_{L}+\theta\right)^{2}-\theta^{2}\right]}, \\
\left(A_{1}^{L}\right)^{S} & =\frac{(1-\lambda \alpha)\left(\theta a_{L}+\theta s a_{L}+2 b_{L} s a_{L}+\theta v \beta-\theta^{2} v-2 \theta b_{L} v\right)+c \theta\left(b_{L}+\theta\right)}{(1-\lambda \alpha)\left[4\left(b_{L}+\theta\right)^{2}-2 \theta^{2}\right]}, \\
\left(A_{2}^{L}\right)^{B(S)} & =\frac{\theta}{2\left(b_{L}+\theta\right)}\left(A_{1}^{L}\right)^{B(S)}+\frac{(1-\lambda \alpha)\left[(1-s) a_{L}+v(\theta+\beta)\right]+c\left(b_{L}+\theta\right)}{2(1-\lambda \alpha)\left(b_{L}+\theta\right)} .
\end{aligned}
$$

Let $\partial \pi_{L} / \partial w=0$, then we get $w_{L}^{*}$. Similarly we can get $w_{H}^{*}$.

\section{Proof of Proposition 12}

Let $\pi_{d}-\pi_{r}>0$, then we can get $s_{0}$, where the profits of hotel from HA and OTA are as follows:

$$
\begin{aligned}
& \pi_{d}=(1-\lambda \alpha)\left(p_{1}^{L} D_{1}^{L}+p_{1}^{H} D_{1}^{H}\right), \\
& \pi_{r}=(1-\lambda \alpha)\left(w_{L} D_{2}^{L}+w_{H} D_{2}^{H}\right) .
\end{aligned}
$$

\section{E. Proof of Corollary 11}

If $\Delta C_{L} \leq \lambda /(1-\lambda) Q_{L}$, then the profit of hotel is $\pi_{11}^{L}$. The derivative of $\pi_{11}^{L}\left(\Delta C_{L}\right)$ is $\partial \pi_{11}^{L} / \partial \Delta C_{L}=(1-\lambda \alpha) p_{1}^{L}>0$. So with the increase of $\Delta C_{L}, \pi_{11}^{L}$ will increase. When $\Delta C_{L}=$ $\lambda /(1-\lambda) Q_{L}, \pi_{11}^{L}$ is maximized. If $\Delta C_{L} \geq \lambda /(1-\lambda) Q_{L}$, then the profit of hotel is $\pi_{12}^{L}$. The derivative of $\pi_{12}^{L}\left(\Delta C_{L}\right)$ is $\partial \pi_{12}^{L} / \partial \Delta C_{L}=(1-\lambda \alpha) p_{1}^{L}-(1-\lambda)\left(p_{1}^{L}+c_{L}\right)<0$. So with the increase of $\Delta C_{L}, \pi_{11}^{L}$ will decline. When $\Delta C_{L}=\lambda /(1-\lambda) Q_{L}$, $\pi_{11}^{L}$ is maximized.

Similarly we can get $\Delta C_{H}^{*}$.

\section{F. Proof of Proposition 13}

Assume that the overbooking proportion is $\gamma_{L}$ and $\gamma_{H}$.

(1) Consider $\left(D_{1}^{L}+D_{2}^{L}+D_{1}^{H}+D_{2}^{H}\right)(1-\lambda) \leq Q$ and $\left(D_{1}^{L}+\right.$ $\left.D_{2}^{L}\right)(1-\lambda)>Q_{L},\left(D_{1}^{H}+D_{2}^{H}\right)(1-\lambda)<Q_{H}$.

That is,

$$
\begin{aligned}
\gamma_{H} & <\frac{\lambda}{1-\lambda}<\gamma_{L} \\
& \leq \frac{\lambda Q_{L}+Q_{H}\left[1-(1-\lambda)\left(1+\gamma_{H}\right)\right]}{(1-\lambda) Q_{L}} .
\end{aligned}
$$

Thus, the hotel would like to overbook to get more profit rather than room vacancy.

(2) Consider $\left(D_{1}^{L}+D_{2}^{L}\right)(1-\lambda)<Q_{L}$ and $\left(D_{1}^{H}+D_{2}^{H}\right)(1-\lambda)>$ $Q_{H}$.

That is, $\gamma_{L}<\lambda /(1-\lambda)<\gamma_{H}$. Then the profit of hotel is

$$
\begin{aligned}
\pi_{112}= & (1-\lambda \alpha)\left(p_{1}^{L} D_{1}^{L}+p_{1}^{H} D_{1}^{H}+w_{L} D_{2}^{L}+w_{H} D_{2}^{H}\right) \\
& -c_{u}^{H}\left[\left(D_{1}^{H}+D_{2}^{H}\right)(1-\lambda)-Q_{H}\right] .
\end{aligned}
$$

Then when $c_{u}^{H}<(1-\lambda \alpha) p_{1}^{H} /(1-\lambda)$, that is, $\pi_{112}-\pi_{111}>0$, the hotel would carry out overbooking.

(3) Consider $\left(D_{1}^{L}+D_{2}^{L}+D_{1}^{H}+D_{2}^{H}\right)(1-\lambda)>Q$ and $\left(D_{1}^{L}+\right.$ $\left.D_{2}^{L}\right)(1-\lambda)>Q_{L},\left(D_{1}^{H}+D_{2}^{H}\right)(1-\lambda)<Q_{H}$. 
That is, $\gamma_{L}>\left(\lambda Q_{L}+Q_{H}\left[1-(1-\lambda)\left(1+\gamma_{H}\right)\right]\right) /(1-\lambda) Q_{L}$ and $\gamma_{H}<\lambda /(1-\lambda)$. Then the profit of hotel is

$$
\begin{aligned}
\pi_{113}= & (1-\lambda \alpha)\left(p_{1}^{L} D_{1}^{L}+p_{1}^{H} D_{1}^{H}+w_{L} D_{2}^{L}+w_{H} D_{2}^{H}\right) \\
& -c_{u}^{L}\left[\left(D_{1}^{L}+D_{2}^{L}+D_{1}^{H}+D_{2}^{H}\right)(1-\lambda)-Q\right] .
\end{aligned}
$$

Then, when $c_{u}^{L}<(1-\lambda \alpha) p_{1}^{L} /(1-\lambda), \pi_{113}-\pi_{111}>0$, thus the hotel would carry out overbooking.

(4) Consider $\left(D_{1}^{L}+D_{2}^{L}+D_{1}^{H}+D_{2}^{H}\right)(1-\lambda)>Q$ and $\left(D_{1}^{L}+\right.$ $\left.D_{2}^{L}\right)(1-\lambda)>Q_{L},\left(D_{1}^{H}+D_{2}^{H}\right)(1-\lambda)>Q_{H}$.

That is, $\gamma_{L}>\left(\lambda Q_{L}+Q_{H}\left[1-(1-\lambda)\left(1+\gamma_{H}\right)\right]\right) /(1-\lambda) Q_{L}$ and $\gamma_{H}>\left(\lambda Q_{H}+Q_{L}\left[1-(1-\lambda)\left(1+\gamma_{L}\right)\right]\right) /(1-\lambda) Q_{H}$.

Then, the profit of hotel is as follows:

$$
\begin{aligned}
\pi_{114}= & (1-\lambda \alpha)\left(p_{1}^{L} D_{1}^{L}+p_{1}^{H} D_{1}^{H}+w_{L} D_{2}^{L}+w_{H} D_{2}^{H}\right) \\
& -c_{u}^{L}\left[\left(D_{1}^{L}+D_{2}^{L}\right)(1-\lambda)-Q_{L}\right] \\
& -c_{u}^{H}\left[\left(D_{1}^{H}+D_{2}^{H}\right)(1-\lambda)-Q_{H}\right] .
\end{aligned}
$$

Then, when $c_{u}^{L}<(1-\lambda \alpha) p_{1}^{L} /(1-\lambda)$ and $c_{u}^{H}<(1-\lambda \alpha) p_{1}^{H} /$ $(1-\lambda), \pi_{114}-\pi_{111}>0$, overbooking is preferred.

\section{G. Threshold Values}

Threshold values are as follows:

$$
\begin{aligned}
L_{1} & =\theta a_{i}+\theta s a_{i}+2 b_{i} s a_{i}+\theta v \beta+3 w_{i} \theta^{2}+3 w_{i} b_{i} \theta \\
& -\theta^{2} v-2 \theta b_{i} v, \\
L_{2} & =2 a_{i}\left(b_{i}+\theta\right)-s a_{i}\left(2 b_{i}+\theta\right)+\theta^{2} w_{i}+2(\theta+\beta)\left(b_{i}\right. \\
& +\theta) v+2 w_{i}\left(b_{i}+\theta\right)^{2}-\theta^{2} v \\
L_{3} & =4 \theta v b_{i} \beta-\theta s a_{i} b_{i}+2 v \beta b_{i}^{2}+3 a_{i} \theta^{2}+4 a_{i} b_{i} \theta \\
& -2 a_{i} b_{i}^{2} s+3 \theta^{2} v \beta+\theta^{2} v b_{i}+2 \theta v b_{i}^{2}+2 a_{i} b_{i}^{2}, \\
L_{4} & =3 a_{i} b_{i} \theta+3 \theta^{2} v \beta-2 \theta v b_{i}^{2}-\theta^{2} v b_{i}+3 a_{i} \theta^{2} \\
& +2 a_{i} b_{i}^{2} s+a b_{i} s \theta+3 b_{i} \beta v \theta, \\
L_{5} & =\theta a_{i}+\theta s a_{i}+2 b_{i} s a_{i}+\theta v \beta-\theta^{2} v-2 \theta b_{i} v, \\
G_{1} & =\left[(1-\lambda \alpha)\left(s a_{i}-\theta v\right)-c \theta\right]\left(B_{1}^{i}\right)^{B(S)} \\
& +\left[(1-\lambda \alpha)\left(a_{i}-s a_{i}+\beta v+\theta v\right)+c\left(b_{i}+\theta\right)\right] \\
& \cdot\left(B_{1}^{i}\right)^{B(S)}+2 \theta(1-\lambda \alpha)\left[\left(A_{1}^{i}\right)^{B(S)}\left(B_{2}^{i}\right)^{B(S)}\right. \\
& \left.+\left(B_{1}^{i}\right)^{B(S)}\left(A_{2}^{i}\right)^{B(S)}\right]-2(1-\lambda \alpha)\left(b_{i}+\theta\right) \\
& \cdot\left[\left(A_{1}^{i}\right)^{B(S)}\left(B_{1}^{i}\right)^{B(S)}+\left(A_{2}^{i}\right)^{B(S)}\left(B_{2}^{i}\right)^{B(S)}\right],
\end{aligned}
$$

$$
\begin{aligned}
G_{2} & =2(1-\lambda \alpha) \\
& \cdot\left\{\left(b_{i}+\theta\right)\left[\left(\left(B_{1}^{i}\right)^{B(S)}\right)^{2}+\left(\left(B_{2}^{i}\right)^{B(S)}\right)^{2}\right]\right. \\
& \left.-2 \theta\left(B_{1}^{i}\right)^{B(S)}\left(B_{2}^{i}\right)^{B(S)}\right\}, \\
s_{0} & =\left(\left(b_{L}+\theta\right)\left(p_{1}^{L}\right)^{2}+\left(b_{H}+\theta\right)\left(p_{1}^{H}\right)^{2}\right. \\
& +\theta w_{L}\left(p_{1}^{L}-p_{2}^{L}\right)+\theta w_{H}\left(p_{1}^{H}-p_{2}^{H}\right) \\
& +\theta v\left(p_{1}^{L}+p_{1}^{H}\right)+\left(w_{L}+w_{H}\right)(\beta+\theta) v \\
& +w_{L}\left(a_{L}-b_{L} p_{2}^{L}\right)+w_{H}\left(a_{H}-b_{H} p_{2}^{H}\right) \\
& \left.-\theta\left(p_{1}^{L} p_{2}^{L}+p_{1}^{H} p_{2}^{H}\right)\right)\left(a_{L}\left(p_{1}^{L}+w_{L}\right)\right. \\
& \left.+a_{H}\left(p_{1}^{H}+w_{H}\right)\right)^{-1} .
\end{aligned}
$$

\section{Competing Interests}

The authors declare that there are no competing interests regarding the publication of this paper.

\section{Acknowledgments}

The authors thank associate editor and anonymous referees for their numerous constructive comments and encouragement that have improved their paper greatly. The work was partly supported by (i) the National Natural Science Foundation of China (71201083, 71572058, and 71571100); (ii) the Fundamental Research Funds for the Central Universities, SCUT (2015ZZ057); (iii) Jiangsu Province Science Foundation for Youths (BK2012379); and (iv) the Fundamental Research Funds for the Central Universities (NS2015076).

\section{References}

[1] J. Li, W. N. Zhang, H. Xu, and J. Jiang, "Dynamic competition and cooperation of road infrastructure investment of multiple tourism destinations: a case Study of Xidi and Hongcun World Cultural Heritage," Discrete Dynamics in Nature and Society, vol. 2015, Article ID 962028, 10 pages, 2015.

[2] T. Paksoy, E. Ozceylan, and G.-W. Weber, "Profit oriented supply chain network optimization," Central European Journal of Operations Research, vol. 21, no. 2, pp. 455-478, 2013.

[3] X. Zhang, H. Song, and G. Q. Huang, "Tourism supply chain management: a new research agenda," Tourism Management, vol. 30, no. 3, pp. 345-358, 2009.

[4] Z. Yang and J. Cai, "Do regional factors matter? Determinants of hotel industry performance in China," Tourism Management, vol. 52, pp. 242-253, 2016.

[5] B. Pan, L. Zhang, and R. Law, "The complex matter of online hotel choice," Cornell Hospitality Quarterly, vol. 54, no. 1, pp. 7483, 2013.

[6] L. Ling, X. Guo, and C. Yang, "Opening the online marketplace: an examination of hotel pricing and travel agency on-line 
distribution of rooms," Tourism Management, vol. 45, pp. 234243, 2014.

[7] L. Ling, Y. Dong, X. Guo, and L. Liang, "Availability management of hotel rooms under cooperation with online travel agencies," International Journal of Hospitality Management, vol. 50, pp. 145-152, 2015.

[8] J. N. K. Liu and E. Y. Zhang, "An investigation of factors affecting customer selection of online hotel booking channels," International Journal of Hospitality Management, vol. 39, pp. 71-83, 2014.

[9] L. Fox, "Four Seasons Unveils \$18 Million Website as Luxury Travel Grows," 2012, http://www.tnooz.com/article/four-seasons-unveils-18-million-dollar-website-as-luxury-travel-grows.

[10] C.-M. Chen and Y.-C. Lin, "The influence of uncertain demand on hotel capacity," International Journal of Hospitality Management, vol. 34, no. 1, pp. 462-465, 2013.

[11] S. Yang, G. Q. Huang, H. Song, and L. Liang, "Game-theoretic approach to competition dynamics in tourism supply chains," Journal of Travel Research, vol. 47, no. 4, pp. 425-439, 2009.

[12] G. Q. Huang, H. Song, and X. Zhang, "A comparative analysis of quantity and price competitions in tourism supply chain networks for package holidays," Service Industries Journal, vol. 30, no. 10, pp. 1593-1606, 2010.

[13] Y. Huang, H. Song, G. Q. Huang, and J. Lou, "A comparative study of tourism supply chains with quantity competition," Journal of Travel Research, vol. 51, no. 6, pp. 717-729, 2012.

[14] H. K. Lee and Y. Fernando, "The antecedents and outcomes of the medical tourism supply chain," Tourism Management, vol. 46, pp. 148-157, 2015.

[15] W.-Y. K. Chiang, D. Chhajed, and J. D. Hess, "Direct marketing, indirect profits: a strategic analysis of dual-channel supplychain design," Management Science, vol. 49, no. 1, pp. 1-20, 2003.

[16] A. A. Tsay and N. Agrawal, "Channel conflict and coordination in the E-commerce age," Production and Operations Management, vol. 13, no. 1, pp. 93-110, 2004.

[17] Q.-H. Li and B. Li, "Dual-channel supply chain equilibrium problems regarding retail services and fairness concerns," Applied Mathematical Modelling, 2016.

[18] S. Panda, N. M. Modak, S. S. Sana, and M. Basu, "Pricing and replenishment policies in dual-channel supply chain under continuous unit cost decrease," Applied Mathematics and Computation, vol. 256, pp. 913-929, 2015.

[19] Y. Liu, C. Ding, C. Fan, and X. Chen, "Pricing decision under dual-channel structure considering fairness and free-riding behavior," Discrete Dynamics in Nature and Society, vol. 2014, Article ID 536576, 10 pages, 2014.

[20] J. Chen, H. Zhang, and Y. Sun, "Implementing coordination contracts in a manufacturer Stackelberg dual-channel supply chain," Omega, vol. 40, no. 5, pp. 571-583, 2012.

[21] Q. Ding, C. Dong, and Z. Pan, "A hierarchical pricing decision process on a dual-channel problem with one manufacturer and one retailer," International Journal of Production Economics, vol. 175, pp. 197-212, 2016.

[22] B. Rodriguez and G. Aydin, "Pricing and assortment decisions for a manufacturer selling through dual channels," European Journal of Operational Research, vol. 242, no. 3, pp. 901-909, 2015.

[23] T. Lockyer, "The perceived importance of price as one hotel selection dimension," Tourism Management, vol. 26, no. 4, pp. 529-537, 2005.
[24] C.-M. Chen, H.-W. Yang, E. Y. Li, and C.-C. Liu, "How does hotel pricing influence guest satisfaction by the moderating influence of room occupancy?" International Journal of Hospitality Management, vol. 49, pp. 136-138, 2015.

[25] J.-M. Espinet, M. Fluviá, R. Rigall-I-Torrent, and A. Saló, "Hotel characteristics and seasonality in prices: an analysis using Spanish tour operators' brochures," Tourism Economics, vol. 18, no. 4, pp. 749-767, 2012.

[26] C. Juaneda, J. M. Raya, and F. Sastre, "Pricing the time and location of a stay at a hotel or apartment," Tourism Economics, vol. 17, no. 2, pp. 321-338, 2011.

[27] G. Abrate, G. Fraquelli, and G. Viglia, "Dynamic pricing strategies: evidence from European hotels," International Journal of Hospitality Management, vol. 31, no. 1, pp. 160-168, 2012.

[28] D. Q. Yao and J. J. Liu, "Competitive pricing of mixed retail and e-tail distribution channels," Omega, vol. 33, no. 3, pp. 235-247, 2005.

[29] J. Zhao and L. Wang, "Pricing and retail service decisions in fuzzy uncertainty environments," Applied Mathematics and Computation, vol. 250, pp. 580-592, 2015.

[30] A. A. Tsay and N. Agrawal, "Channel dynamics under price and service competition," Manufacturing \& Service Operations Management, vol. 2, no. 4, pp. 372-391, 2000.

[31] S. C. Choi, "Price competition in a duopoly common retailer channel," Journal of Retailing, vol. 72, no. 2, pp. 117-134, 1996.

[32] Y. Bakos and E. Brynjolfsson, "Bundling and competition on the internet," Marketing Science, vol. 19, no. 1, pp. 63-82, 2000.

[33] H. Song, J. H. Kim, and S. Yang, "Confidence intervals for tourism demand elasticity," Annals of Tourism Research, vol. 37, no. 2, pp. 377-396, 2010.

[34] D. M. Hanssens, L. J. Parsons, and R. L. Schultz, Market Response Models: Econometric and Time Series Analysis, Kluwer Academic Publishers, Boston, Mass, USA, 2nd edition, 2001.

[35] H. Kurata, D.-Q. Yao, and J. J. Liu, "Pricing policies under direct vs. indirect channel competition and national vs. store brand competition," European Journal of Operational Research, vol. 180, no. 1, pp. 262-281, 2007.

[36] R. Law and C. Cheung, "A study of the perceived importance of the overall website quality of different classes of hotels," International Journal of Hospitality Management, vol. 25, no. 3, pp. 525-531, 2006.

[37] K. B. Chen, "Procurement strategies and coordination mechanism of the supply chain with one manufacturer and multiple suppliers," International Journal of Production Economics, vol. 138, no. 1, pp. 125-135, 2012. 


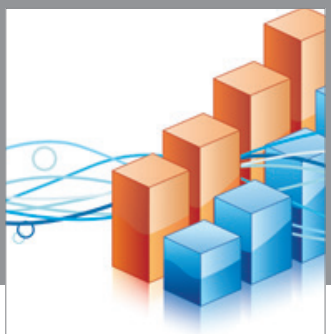

Advances in

Operations Research

vatem alat4

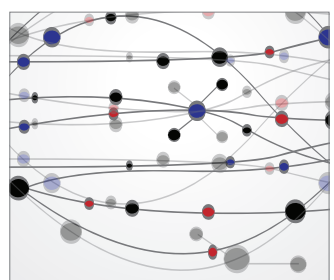

\section{The Scientific} World Journal
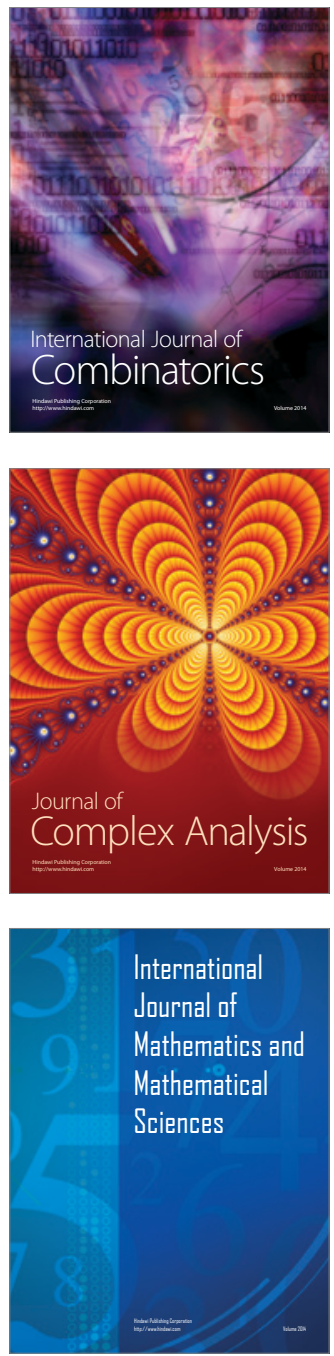
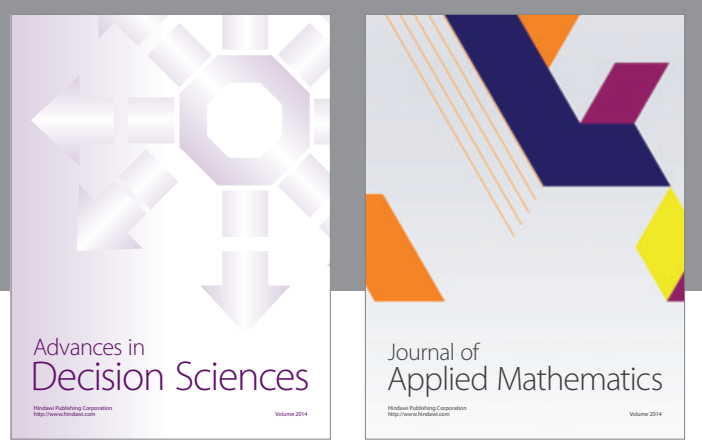

Algebra

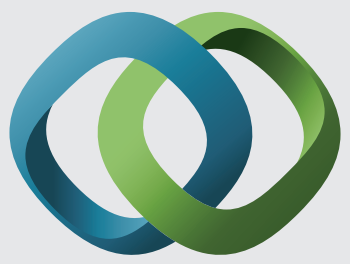

\section{Hindawi}

Submit your manuscripts at

http://www.hindawi.com
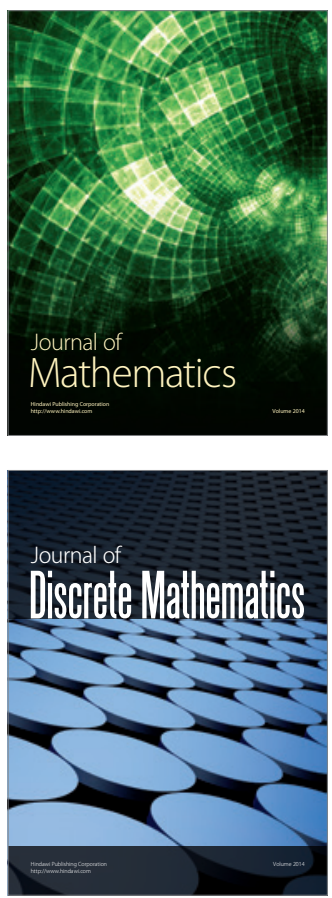

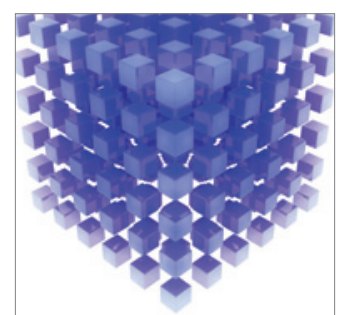

Mathematical Problems in Engineering
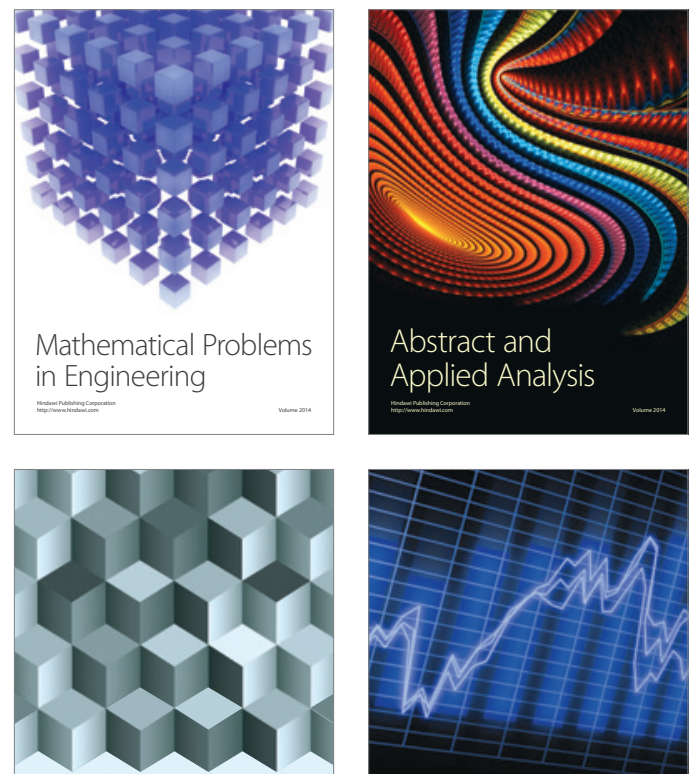

Journal of

Function Spaces

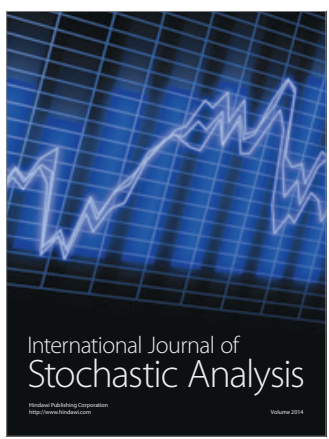

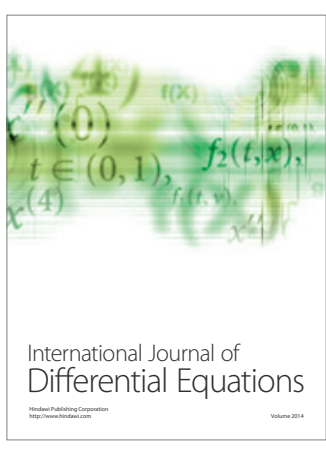
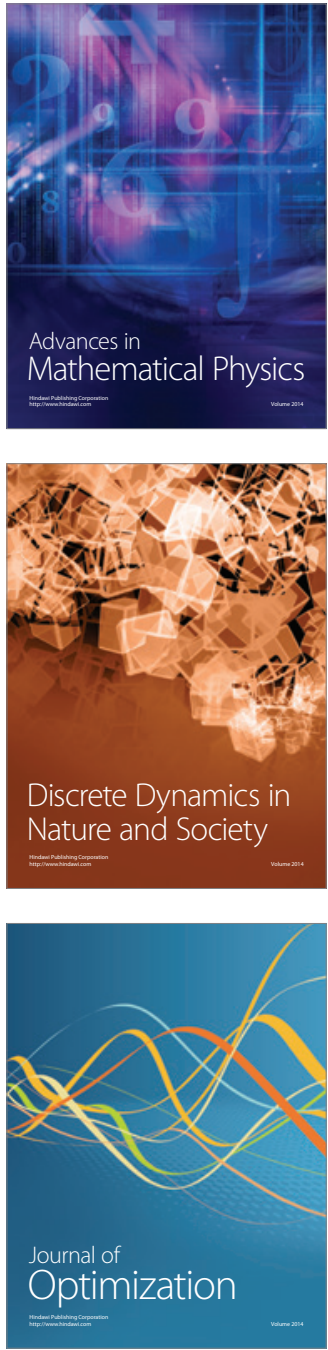